\title{
Article \\ A Cooperative Partner Selection Study of Military-Civilian Scientific and Technological Collaborative Innovation Based on Interval-Valued Intuitionistic Fuzzy Set
}

\author{
Bing Li $(\mathbb{D}$ and Jihai Zhang * (1) \\ School of Management and Economics, Beijing Institute of Technology, Beijing 100081, China; \\ 3120170744@bit.edu.cn \\ * Correspondence: zhangjihai@bit.edu.cn
}

Citation: Li, B.; Zhang, J. A Cooperative Partner Selection Study of Military-Civilian Scientific and Technological Collaborative Innovation Based on Interval-Valued Intuitionistic Fuzzy Set. Symmetry 2021, 13, 553. https://doi.org/ $10.3390 /$ sym 13040553

Academic Editor: Paweł Ziemba

Received: 28 February 2021

Accepted: 24 March 2021

Published: 27 March 2021

Publisher's Note: MDPI stays neutral with regard to jurisdictional claims in published maps and institutional affiliations.

Copyright: (c) 2021 by the authors. Licensee MDPI, Basel, Switzerland. This article is an open access article distributed under the terms and conditions of the Creative Commons Attribution (CC BY) license (https:/ / creativecommons.org/licenses/by/ $4.0 /)$.

\begin{abstract}
Military-civilian scientific and technological collaborative innovation (MCSTCI) is an important intersection of civil-military integrated development strategies and innovation-driven development strategies, and has become a brand-new model for Chinese key scientific and technological research. The selection of cooperative partner between military and civilian innovation entities is not only the primary segment to carry out MCSTCI activities, but also an important foundation for achieving complementary advantages and win-win cooperation. Therefore, on the basis of summarizing and combing the evaluation indicators, a partner selection model based on interval-valued intuitionistic fuzzy set multi-attribute decision-making is proposed. Firstly, we improve the traditional scoring function, and combine the new scoring function and entropy weight method to determine the weight of each evaluation indicator. Secondly, considering the impact of decision-makers' risk attitudes, a method of transforming evaluation matrix based on hesitancy distribution is proposed. Finally, the grey correlation and TOPSIS (Technique for Order Preference by Similarity to an Ideal Solution) method is used to mark and rank the candidates, and the innovation entities with the highest score is selected as the collaborative innovation partner. An example of a military equipment manufacturing enterprise in Beijing for partner selection in order to carry out joint technological research on a certain anti-ship missile weapon shows that the model is more comprehensive and flexible in solving fuzzy multi-attribute decision-making problems, and can assess and select cooperative partners for MCSTCI scientifically and objectively.
\end{abstract}

Keywords: interval-valued intuitionistic fuzzy set; military-civilian scientific and technological collaborative innovation; cooperative partner selection; risk attitudes; fuzzy multi-attribute decision-making

\section{Introduction}

The form of war and the way of combat have changed profoundly with the extensive application of science and technology, which in turn has increasingly become an important factor affecting the outcomes of war and the strategies of national defense construction. To this end, it is necessary to integrate national defense and civilian science and technology. For example, China's first self-developed aircraft carrier has accelerated the development of its naval equipment modernization as the main components are supplied by the research institutes of over 500 supporting units in over 20 provinces (municipalities and autonomous regions), most of which are non-military enterprises [1]. The Manhattan Project, Apollo Program, Shenzhou Program, Chinese Lunar Exploration Program, and the Chinese intercontinental ballistic missile development are all inseparable from the participation and contribution of civilian units [2]. The defense or civilian innovation system cannot complete national scientific research tasks alone; a wide range of scientific and technological innovation forces must be mobilized. 
In 2017, the Chinese government put forward the general goal of civil-military integration development in the new era [3]. Military-civilian scientific and technological collaborative innovation (MCSTCI) is an important intersection of innovation-driven development strategies and civil-military integration development strategies and is of great significance to the construction of an innovative country. From a worldwide perspective, major developed countries have taken MCSTCI as the focus of investment and the basis of comprehensive integration. MCSTCI strategies have been formulated according to national development needs, and relatively complete and mature MCSTCI systems and models have been formed, such as the civil-military integration model of the United States [4], the covering up of the military with the civilian model of Japan [5], and the military first, then civilian model of Russia [6]. Therefore, MCSTCI is a necessary way to address major national strategic needs and major frontier scientific issues.

China's national defense innovation system has long been operating independently from the civilian innovation system, which leads to difficulties in linking scientific research management systems, serious duplication of investment, high barriers for the transformation and sharing of scientific and technological achievements, difficulties in sharing equipment and facilities, and rigid mechanisms for the flow of scientific research talents. Despite the large investment in national science and technology innovation funds, the effect is unsatisfactory. This pattern is no longer suitable for the national security and development situation in the new era. China urgently needs to break the barriers of military-civilian technology sharing and crack the problem of military-civilian two-way transfer and transformation. MCSTCI is the most direct form of knowledge and technical cooperation between military and civilian innovation organizations and resource sharing between organizations through the spillover of knowledge and technology [7]. For the organizations in the MCSTCI system, correctly choosing partners is crucial for knowledge and technology cooperation. For example, after the BeiDou-2 Navigation Satellite System project was approved by the State Council and the Central Military Commission in 2004 [8], military and military-industrial units such as the Chinese Academy of Space Technology, China Academy of Launch Vehicle Technology, China Electronics Technology Group Corporation, Harbin Institute of Technology, and Beihang University participated in that undertaking. However, several key technologies and important components of the BeiDou navigation satellite system rely on domestic technically superior units. The collaborative competition and collective intelligence overcame the relevant technical bottlenecks and achieved the optimal allocation of scientific and technological resources. For this reason, the Beidou Navigation Satellite System was included as one of the 16 major science and technology projects in the National Guideline on Medium and Long-Term Program for Science and Technology Development (2006-2020). Private entities such as Tsinghua University, Chinese Academy of Sciences, Wuhan University, Beijing BDStar Navigation Technology Co. Ltd., and Hwa Create Co. Ltd. have also participated in the BeiDou project [9].

Since the defense or civilian system alone does not have all the scientific and technological resources required for innovation and R\&D (research and development), seeking external R\&D partners across systems makes up for the lack of resources and improves the research capabilities of core technologies. Therefore, this study addresses the uncertainty problem that is particularly prominent in multi-attribute decision making in the field of MCSTCI and proposes a partner selection method based on interval-valued intuition fuzzy sets for decision-makers to promote the integration of scientific and technological resources. This study is expected to provide a scientific paradigm for carrying out major national scientific and technological research.

This paper is organized as follows. In Section 2, a literature review was conducted on MCSTCI, partner selection, and intuitionistic fuzzy set approach to provide theoretical support for this paper. In Section 3, the preliminary definitions of the literature in IFSs (intuitionistic fuzzy sets) and IVIFSs (interval-valued intuitionistic fuzzy sets) were briefly reviewed. In Section 4, the evaluation indexes of MCSTCI partners are summarized and 
sorted out, and the background and principles of evaluation selection are clarified. In Section 5, a model for the selection of MCSTCI partners is constructed based on IVIFSs. In this model, the traditional scoring function is improved by taking into account the influence of accuracy function and interval length; the objective weights of the indicators are determined with the entropy weight method; the risk attitude of decision-makers is portrayed by hesitancy degree allocation in the assembly stage of the evaluation matrix; the grey correlation and TOPSIS method is selected as the decision-making method for the selection of military-civilian collaborative innovation partners. In Section 6, as a numerical example, partner selection for a military equipment manufacturing enterprise in Beijing is conducted to verify the effectiveness and practical application value of the military-civilian technological collaborative innovation partner selection model.

\section{Literature Review}

At present, research on MCSTCI can be summarized into three aspects: influencing factors, collaborative process, and collaborative results. In terms of influencing factors, Zhou et al. [10] explored the path evolution and driving factors of civil-military integration technology transfer in different times based on the development process of civil-military integration technology transfer of Sichuan Zhongwu Technology in China from 2004 to 2017; Fang et al. [11] constructed a model for the influencing factors of knowledge transfer under the perspective of military-civilian collaborative innovation. In terms of the collaborative process, Kulve and Smit [12] applied the social network theory to analyze the military-civilian interaction network developed for high-energy batteries in the Netherlands and pointed out the importance of the dual-use innovative technological network. Zhao et al. [13] focused on the technology sharing issues between Chinese military enterprises and civil enterprises and constructed a differential game model to explore the optimal strategy, cooperation benefits, and distribution mechanism. Based on the evolutionary game theory, Fang and Wang [14] built an evolutionary game model of China's satellite industry military-civilian collaborative innovation with military enterprises and civil enterprises as the main participators under bounded rationality. Zhao et al. [15] revealed that the defense innovation industry network is a complex network intertwined with horizontal and vertical networks, which usually has a relatively reasonable network homogeneity and network openness and gradually enters a dynamic equilibrium state under the interaction of self-organization and the organizational evolution mechanism. In terms of collaborative results, Wang and Chen [16] explained the emergence and attributes of military-civilian integrated enterprises, proposed explanatory factors of technical efficiency, and constructed a stochastic frontier model considering technical inefficiency. Lavallee [17] thoroughly explored the relationship between the post-Cold War civil-military integration policy agenda and DoD's increased reliance upon private military contractors.

Research on MCSTCI covers various fields, including the sharing and transfer of knowledge and technology, the construction and evolution of collaborative innovation networks, and the technical efficiency of civil-military integration enterprises. However, the selection of innovation partners is rarely studied. Partner selection between military and civilian entities is the primary step to carry out MCSTCI activities and an important means of external technological resources for the innovation entities. Reasonably selecting innovation partners improves the efficiency and stability of MCSTCI, which is of great significance to the advancement of military-civilian technological integration.

Although rarely studied in the field of MCSTCI, research on the strategies and methods of partner selection in commercial organizations such as supply chains, virtual enterprises, and industrial alliances is extensive. According to the objectives and characteristics of supply chain collaborative product innovation, Lv and Qi [18] constructed a supply chain collaborative product innovation partner selection index system based on innovative resources. Nikghadam et al. [19] designed a virtual enterprise partner selection method that integrates the fuzzy analytic hierarchy process and the goal planning model (F-AHPGP). Han and Chen [20] explored the knowledge-sharing partner selection mechanism of 
industrial cluster enterprises under the influence of invisible contracts using the Hoteling game model. Zhu et al. [21] proposed an innovative alliance partners model based on the ELECTRE-I method. Xiao et al. [22] introduced the green criterion into the partner selection problem (PSP) and proposed a green partner selection model based on six criteria. Partner selection is a typical multi-attribute decision-making problem studied by establishing an evaluation index system and selecting the appropriate evaluation methods. Regarding the problem of partner selection for MCSTCI, some evaluation indexes involving the military often cannot be assigned specific values, such as civil-military integration policies and willingness, resulting in greater vagueness and uncertainty compared with the ordinary commercial enterprise partner selection problems. However, the existing methods have certain shortcomings in describing the vagueness and uncertainty, and a more suitable method is needed.

Atanassov [23,24] first proposed the concept of intuitionistic fuzzy sets (IFSs) in 1986 and expanded it into interval-valued intuitionistic fuzzy sets (IVIFSs) in 1989, which carve out the vagueness of realistic decisions through mathematical thinking. IFSs and IVIFSs have been widely used in e-commerce [25], social networks [26], clean energy [27], industrial engineering [28], and other fields. The interval numbers expressing the three states of support, opposition, and neutrality can be used to express membership degree, non-membership degree, and hesitancy degree, which is more flexible and delicate in dealing with vagueness and uncertainty. Based on the connotation of scoring function and exact function, Gong and Ma [29] proposed the new scoring function and exact function using probability theory and total probability formula and proved its axiomatic properties. Gao et al. [30] established the combined weight optimization model in which the goal is based on maximizing the integrated prospect value, and the subject conditions include the interval criteria weights and the decision-maker's subjective preference. Chen and Huang [31] proposed a new MADM method based on IVIFVs and linear programming methodology, where the weights of attributes and the evaluating values of attributes of the alternatives given by the decision-maker are represented by IVIFVs. Zhou et al. [32] established a novel weighting approach to group decision-making (GDM) with interval-valued intuitionistic fuzzy preference relations (IVIFPRs) based on a fuzzy cooperative game method and the continuous interval-valued intuitionistic fuzzy ordered weighted averaging (CIVIFOWA) operator.

In summary, this paper provides a partner selection method based on interval intuitionistic fuzzy sets in response to the uncertainty problem particularly prominent in the multi-attribute decision making in MCSTCI. The research content and main innovations of this paper include: first, the research on partner selection is introduced into the field of MCSTCI, filling the research gap in this field. Secondly, based on the improved interval intuition fuzzy set method, a selection model is constructed, and the risk attitude of decision-makers is portrayed by the hesitation degree allocation. Then, the grey correlation and TOPSIS method is used to score and sort the candidates, and the innovation subject with the highest score is selected as the partner of collaborative innovation. Finally, as a numerical example, partner selection for a military equipment manufacturing enterprise in Beijing is conducted to verify the effectiveness and practical application value of the military-civilian technological collaborative innovation partner selection model. This study aims to provide a reference for the civilian, military, and military-industrial units, promote the integration of scientific and technological resources and scientific and technological forces, and provide a scientific paradigm for the development of major national scientific and technological research.

\section{Preliminaries}

In this section, we briefly review the concept of IFSs and IVIFSs, briefly review the scoring function and accuracy function of IVIFSs, and briefly review the intervalvalued intuitionistic fuzzy weighted averaging (IVIFWA) operator of IVIFSs from accuracy function. 
Definition 1 ([23]). An IFSs A defined on X is

$$
A=\left\{<x, u_{A}(x), v_{A}(x)>\mid x \in X\right\}
$$

When $X$ is a non-empty set called the universe of discourse; $u_{A}(x): X \rightarrow[0,1]$ and $v_{A}(x): X \rightarrow[0,1] ; 0 \leq u_{A}(x)+v_{A}(x) \leq 1 ; \forall x \in X . u_{A}(x)$ and $v_{A}(x)$ are called respectively the membership degree and non-membership degree of $x$ to A. Hesitancy degree or intuitionistic index of $x$ to $A$ is defined as $\pi_{A}(x)=1-u_{A}(x)-v_{A}(x)$ for all $x \in X, 0 \leq \pi_{A}(x) \leq 1$. The intuitionistic fuzzy set on the universe $X$ is IFS(X).

Definition 2 ([24]). An IVIFSs $\widetilde{A}$ defined on $\mathrm{X}$ is the membership degree and non-membership degree represent the decision maker's preferences, and the fuzziness is reflected because neither the membership degree nor non-membership degree is an exact value.

$$
\widetilde{A}=\left\{<x, \widetilde{u}_{\widetilde{A}}(x), \widetilde{v}_{\widetilde{A}}(x)>\mid x \in X\right\}
$$

where $X$ is a non-empty set called the universe of discourse; $\widetilde{u}_{\widetilde{A}}(x): X \rightarrow \operatorname{int}([0,1])$ and $\widetilde{v}_{\widetilde{A}}(x): X \rightarrow \operatorname{int}([0,1]) ; 0 \leq \sup \widetilde{u}_{\widetilde{A}}(x)+\sup \widetilde{v}_{\widetilde{A}}(x) \leq 1, \forall x \in X . \widetilde{u}_{\widetilde{A}}$ and $\widetilde{v}_{\widetilde{A}}$ are the membership function and the non-membership function of the IVIFSs $\widetilde{A}$ respectively, $\widetilde{u}_{\widetilde{A}}(x)$ and $\widetilde{v}_{\widetilde{A}}(x)$ are the interval-valued membership degree and the interval-valued non-membership degree of element $x$ belonging to the IVIFSs $\widetilde{A}$ respectively. int $([0,1])$ represents the set of all closed subsets of the $[0,1]$ interval. For convenience, the IVIFSs can be recorded as:

$$
\widetilde{A}=\left\{<x,\left[\widetilde{u}_{\widetilde{A}}^{L}(x), \widetilde{u}_{\widetilde{A}}^{U}(x)\right],\left[\widetilde{v}_{\widetilde{A}}^{L}(x), \widetilde{v}^{U} \widetilde{A}^{(x)}\right]>\mid x \in X\right\}
$$

Among them, $\left[\widetilde{u}^{L} \widetilde{A}(x), \widetilde{u}^{U} \widetilde{A}(x)\right] \subseteq[0,1],\left[\widetilde{v}^{L} \widetilde{A}(x), \widetilde{v}^{U} \widetilde{A}(x)\right] \subseteq[0,1]$ and $0 \leq \widetilde{u}^{U} \widetilde{A}_{\widetilde{A}}(x)+$ $\widetilde{v}_{\widetilde{A}}^{U}(x) \leq 1 . \quad \widetilde{\pi}_{\widetilde{A}}(x)=\left[\widetilde{\pi}^{L} \widetilde{A}^{\prime} \widetilde{\pi}^{U} \widetilde{A}_{\widetilde{A}}\right]=\left[1-\widetilde{u}^{U} \widetilde{A}^{(x)}\left(\widetilde{v}^{U} \widetilde{A}(x), 1-\widetilde{u}^{L} \widetilde{A}^{2}(x)-\widetilde{v}^{L} \widetilde{A}^{\prime}(x)\right]\right.$ is the hesitation interval of element $x$ belonging to $\widetilde{A}$, satisfying $\widetilde{\pi}_{\widetilde{A}}(x) \subseteq[0,1]$. Generally, the order pair $\left(\left[\widetilde{u}_{\widetilde{A}}^{L}(x), \widetilde{u}_{\widetilde{A}}^{U}(x)\right],\left[\widetilde{v}_{\widetilde{A}}^{L}(x), \widetilde{v}^{U} \widetilde{A}_{\widetilde{A}}(x)\right]\right)$ formed by the membership interval and the non-membership interval of the element $x$ to $\widetilde{A}$ is called interval intuitionistic fuzzy number. In particular, if there are $\widetilde{u}^{L} \widetilde{A}(x)=\widetilde{u}^{U} \widetilde{A}(x)$ and $\widetilde{v}^{L} \widetilde{A}(x)=\widetilde{v}_{\widetilde{A}}^{U}(x)$ for $\forall x \in X$, then the interval intuitionistic fuzzy set degenerates into an intuitionistic fuzzy set.

Definition 3 ([33]). Let $\widetilde{\alpha}_{1}=\left(\left[\widetilde{u}_{\widetilde{\alpha}_{1}}^{L}, \widetilde{u}_{\widetilde{\alpha}_{1}} U_{,},\left[\widetilde{v}_{\widetilde{\alpha}_{1}}, \widetilde{v}_{\widetilde{\alpha}_{1}}\right]\right)\right.$ and $\widetilde{\alpha}_{2}=\left(\left[\widetilde{u}_{\widetilde{\alpha}_{2}}^{L}, \widetilde{u}_{\widetilde{\alpha}_{2}}\right],\left[\widetilde{v}_{\widetilde{\alpha}_{2}}, \widetilde{v}_{\widetilde{\alpha}_{2}}\right]\right)$ be any interval intuitionistic fuzzy numbers, then (1-4) are the operation rules followed by interval fuzzy numbers, where (1) is an addition operation, (2) is a multiplication operation, (3) is a number multiplication operation, and (4) is an exponential operation.

(1) $\widetilde{\alpha}_{1} \oplus \widetilde{\alpha}_{2}=\left(\left[\widetilde{u}_{\widetilde{\alpha}_{1}}^{L}+\widetilde{u}_{\widetilde{\alpha}_{2}}^{L}-\widetilde{u}_{\widetilde{\alpha}_{1}}^{L} \widetilde{u}_{\widetilde{\alpha}_{2}}^{L} \widetilde{u}_{\widetilde{\alpha}_{1}}+\widetilde{u}_{\widetilde{\alpha}_{2}}-\widetilde{u}_{\widetilde{\alpha}_{1}} \widetilde{u}_{\widetilde{\alpha}_{2}}\right],\left[\widetilde{v}^{L} \widetilde{\alpha}_{1} \widetilde{v}_{\widetilde{\alpha}_{2}}^{L}, \widetilde{v}^{U} \widetilde{\alpha}_{1} \widetilde{v}_{\widetilde{\alpha}_{2}} U_{\widetilde{\alpha}_{2}}\right]\right)$

(2) $\widetilde{\alpha}_{1} \otimes \widetilde{\alpha}_{2}=\left(\left[\widetilde{u}^{L} \widetilde{\alpha}_{1} \widetilde{u}_{\widetilde{\alpha}_{2}}^{L}, \widetilde{u}_{\widetilde{\alpha}_{1}} \widetilde{u}_{\widetilde{\alpha}_{2}}\right],\left[\widetilde{v}_{\widetilde{\alpha}_{1}}^{L}+\widetilde{v}_{\widetilde{\alpha}_{2}}^{L}-\widetilde{v}_{\widetilde{\alpha}_{1}}^{L} \widetilde{v}_{\widetilde{\alpha}_{2}}, \widetilde{v}_{\widetilde{\alpha}_{1}}+\widetilde{v}_{\widetilde{\alpha}_{2}}-\widetilde{v}_{\widetilde{\alpha}_{1}}^{L} \widetilde{v}_{\widetilde{\alpha}_{2}}^{L}\right]\right)$

(3) $\lambda \widetilde{\alpha}_{1}=\left(\left[1-\left(1-\widetilde{u}_{\widetilde{\alpha}_{1}}^{L}\right)^{\lambda}, 1-\left(1-\widetilde{u}_{\widetilde{\alpha}_{1}}\right)^{\lambda}\right],\left[\left(\widetilde{v}^{L} \widetilde{\alpha}_{1}\right)^{\lambda},\left(\widetilde{v}_{\widetilde{\alpha}_{1}}\right)^{\lambda}\right]\right)$

(4) $\widetilde{\alpha}_{1}^{\lambda}=\left(\left[\left(\widetilde{u}^{L} \widetilde{\alpha}_{1}\right)^{\lambda},\left(\widetilde{u}_{\widetilde{\alpha}_{1}}\right)^{\lambda}\right],\left[1-\left(1-\widetilde{v}_{\widetilde{\alpha}_{1}}^{L}\right)^{\lambda}, 1-\left(1-\widetilde{v}_{\widetilde{\alpha}_{1}}\right)^{\lambda}\right]\right)$

Definition 4 ([33]). Let $\widetilde{\alpha}=\left(\left[\widetilde{u}_{\widetilde{\alpha}}^{L}, \widetilde{u}_{\widetilde{\alpha}}^{U}\right],\left[\widetilde{v}_{\widetilde{\alpha}}^{L}, \widetilde{v}_{\widetilde{\alpha}}\right]\right)$ be an interval intuitionistic fuzzy number, then its scoring function $S(\widetilde{\alpha})$ and exact function $H(\widetilde{\alpha})$ can be expressed as:

$$
\begin{aligned}
& S(\widetilde{\alpha})=\frac{\widetilde{u}_{\widetilde{\alpha}}^{L}+\widetilde{u}_{\widetilde{\alpha}} U_{\widetilde{v}} \widetilde{v}_{\widetilde{\alpha}}-\widetilde{v}_{\widetilde{\alpha}}}{2} \\
& H(\widetilde{\alpha})=\frac{\widetilde{u}_{\widetilde{\alpha}}^{L}+\widetilde{u}_{\widetilde{\alpha}}+\widetilde{v}_{\widetilde{\alpha}}^{L_{\widetilde{\alpha}}}+\widetilde{v}_{\widetilde{\alpha}}}{2}
\end{aligned}
$$

$S(\widetilde{\alpha}) \in[-1,1], H(\widetilde{\alpha}) \in[-1,1]$. For any interval intuitionistic fuzzy number $\widetilde{\alpha}_{1}$ and $\widetilde{\alpha}_{2}$, there are the following comparison rules: 
(1) IF $S\left(\widetilde{\alpha}_{1}\right)>S\left(\widetilde{\alpha}_{2}\right)$, then $\widetilde{\alpha}_{1}>\widetilde{\alpha}_{2} ;$ IF $S\left(\widetilde{\alpha}_{1}\right)<S\left(\widetilde{\alpha}_{2}\right)$, then $\widetilde{\alpha}_{1}<\widetilde{\alpha}_{2}$.

(2) IF $S\left(\widetilde{\alpha}_{1}\right)=S\left(\widetilde{\alpha}_{2}\right)$, then when $H\left(\widetilde{\alpha}_{1}\right)>H\left(\widetilde{\alpha}_{2}\right), \widetilde{\alpha}_{1}>\widetilde{\alpha}_{2} ;$ when $H\left(\widetilde{\alpha}_{1}\right)<H\left(\widetilde{\alpha}_{2}\right), \widetilde{\alpha}_{1}<\widetilde{\alpha}_{2}$; when $H\left(\widetilde{\alpha}_{1}\right)=H\left(\widetilde{\alpha}_{2}\right), \widetilde{\alpha}_{1}=\widetilde{\alpha}_{2}$.

Definition 5 ([33]). Let $\widetilde{\alpha}_{i}=\left(\left[\widetilde{u}_{\widetilde{\alpha}_{i}}^{L}, \widetilde{u}_{\widetilde{\alpha}_{i}}^{U}\right],\left[\widetilde{v}_{\widetilde{\alpha}^{\prime}} \widetilde{v}_{\widetilde{\alpha}_{i}}\right]\right)(i=1,2, \cdots, n)$ is a set of interval intuitionistic fuzzy numbers, then the interval-valued intuitionistic fuzzy weighted averaging (IVIFWA) is recorded as:

$$
\operatorname{IVIFWA} A_{W}\left(\widetilde{\alpha}_{1}, \widetilde{\alpha}_{2}, \cdots, \widetilde{\alpha}_{n}\right)=\left(\left[1-\prod_{i=1}^{n}\left(1-\widetilde{u}_{\widetilde{\alpha}_{i}}^{L}\right)^{\omega_{i}}, 1-\prod_{i=1}^{n}\left(1-\widetilde{u}_{\widetilde{\alpha}_{i}}^{U}\right)^{\omega_{i}}\right],\left[\prod_{i=1}^{n}\left(\widetilde{v}_{\widetilde{\alpha}_{i}}^{L}\right)^{\omega_{i}},\left(\widetilde{v}_{\widetilde{\alpha}_{i}}^{U}\right)^{\omega_{i}}\right]\right)
$$

Among them, $\boldsymbol{\omega}=\left(\omega_{1}, \omega_{2}, \cdots \omega_{n}\right)^{\mathrm{T}}$ is a weight vector of $\widetilde{\alpha}_{i}(i=1,2, \cdots, n)$, satisfying $\omega_{i} \in[0,1]$ and $\sum_{i=1}^{n} \omega_{i}=1(i=1,2, \cdots, n)$.

Definition 6 ([34]). Let $\widetilde{\alpha}_{1}=\left(\left[\widetilde{u}_{\widetilde{\alpha}_{1},}^{L} \widetilde{u}_{\widetilde{\alpha}_{1}}\right],\left[\widetilde{v}_{\widetilde{\alpha}_{1}}, \widetilde{v}_{\widetilde{\alpha}_{1}}\right]\right)$ and $\widetilde{\alpha}_{2}=\left(\left[\widetilde{u}_{\widetilde{\alpha}_{2}}^{L} \widetilde{u}_{\widetilde{\alpha}_{2}}\right],\left[\widetilde{v}_{\widetilde{\alpha}_{2}}, \widetilde{v}_{\widetilde{\alpha}_{2}}\right]\right)$ be any interval intuitionistic fuzzy numbers, then the Euclidean distance between these two intervals intuitionistic fuzzy numbers is defined as:

$$
d\left(\widetilde{\alpha}_{1}, \widetilde{\alpha}_{2}\right)=\sqrt{\frac{1}{4}\left[\begin{array}{r}
\left(\widetilde{u}_{\widetilde{\alpha}_{1}}^{L}-\widetilde{u}_{\widetilde{\alpha}_{2}}^{L}\right)^{2}+\left(\widetilde{u}^{U} \widetilde{\alpha}_{\widetilde{\alpha}_{1}}-\widetilde{u}_{\widetilde{\alpha}_{2}}\right)^{2}+\left(\widetilde{v}^{L} \widetilde{\alpha}_{\widetilde{\alpha}_{1}}-\widetilde{v}^{L} \widetilde{\alpha}_{2}\right)^{2} \\
+\left(\widetilde{v}_{\widetilde{\alpha}_{1}}-\widetilde{v}_{\widetilde{\alpha}_{2}}\right)^{2}+\left(\widetilde{\pi}_{\widetilde{\alpha}_{1}}^{L}-\widetilde{\pi}_{\widetilde{\alpha}_{2}}^{L}\right)^{2}+\left(\widetilde{\pi}_{\widetilde{\alpha}_{1}}^{L_{1}}-\widetilde{\pi}^{U} U_{\widetilde{\alpha}_{2}}\right)^{2}
\end{array}\right]}
$$

Among them, $\widetilde{\pi}_{\widetilde{\alpha}_{1}}^{L_{1}}=1-\widetilde{u}_{\widetilde{\alpha}_{1}}^{U_{1}}-\widetilde{v}_{\widetilde{\alpha}_{1}}, \widetilde{\pi}_{\widetilde{\alpha}_{1}}^{U_{1}}=1-\widetilde{u}_{\widetilde{\alpha}_{1}}^{L}-\widetilde{v}_{\widetilde{\alpha}_{1}}^{L} . \widetilde{\pi}_{\widetilde{\alpha}_{2}}^{L_{\alpha_{2}}}$ and $\widetilde{\pi}_{\widetilde{\alpha}_{2}}^{U_{2}}$ are the same.

\section{Index Selection}

The military-civilian scientific and technological collaborative innovation system (MCSTCIS) gathers innovative entities such as military and local universities, research institutions, enterprises to participate in the whole scientific research and innovation process of basic research, applied research, technology development, testing and verification, and finalization of scientific research results, as shown in Figure 1. With the continuous joining of military and civilian entities, the transformation, utilization, and dissipation of information flow, technology flow, and capital flow among innovative entities will show diversified characteristics. In order to enhance the core competitiveness of products and obtain economic benefits, each entity will continuously adjust its own strategies to better adapt to the complexity of the collaborative innovation system. Through the continuous extension of the innovation chain and the intersection of business, the innovation entities will break through the original system boundaries and place its own resource allocation within the framework of meeting the major national tasks. In this way, with the continuous selection and joining of innovation partners, the boundary between military and civilian scientific and technological innovation system gradually blurs, and ultimately the integration of military-civilian science and technology is realized.

The selection of partners between MCSTCI entities depends on three aspects: first, the external environment, which is mainly determined by the current Chinese strategic deployment, is the external constraint of MCSTCI activities; second, its own endowment, which lays the foundation for innovation entities to participate in cooperation, is also the core element to be evaluated for partner selection; third, the level of cooperation, which can reflect whether each innovation entity has created more value through cooperation, determines the longevity and stability of the cooperative relationship. The above study combined with the existing literature to summarize, this paper selects four first-level indicators and seven second-level indicators as the evaluation indicators for the selection of MCSTCI partners, as shown in Table 1. 


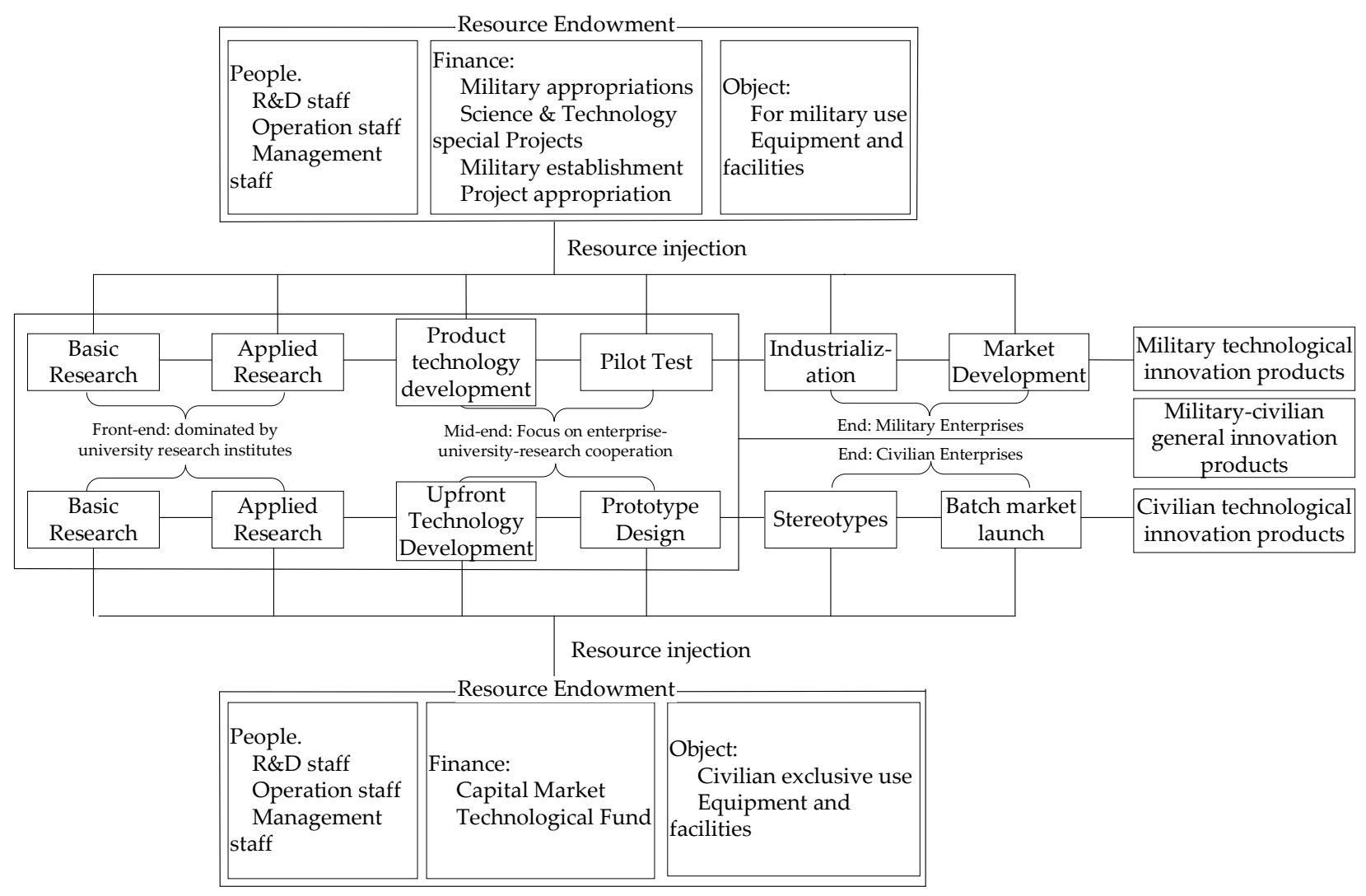

Figure 1. Structural analysis of the military-civilian technological collaborative innovation system.

Table 1. Indicators for the selection of military-civilian scientific and technological collaborative innovation partners.

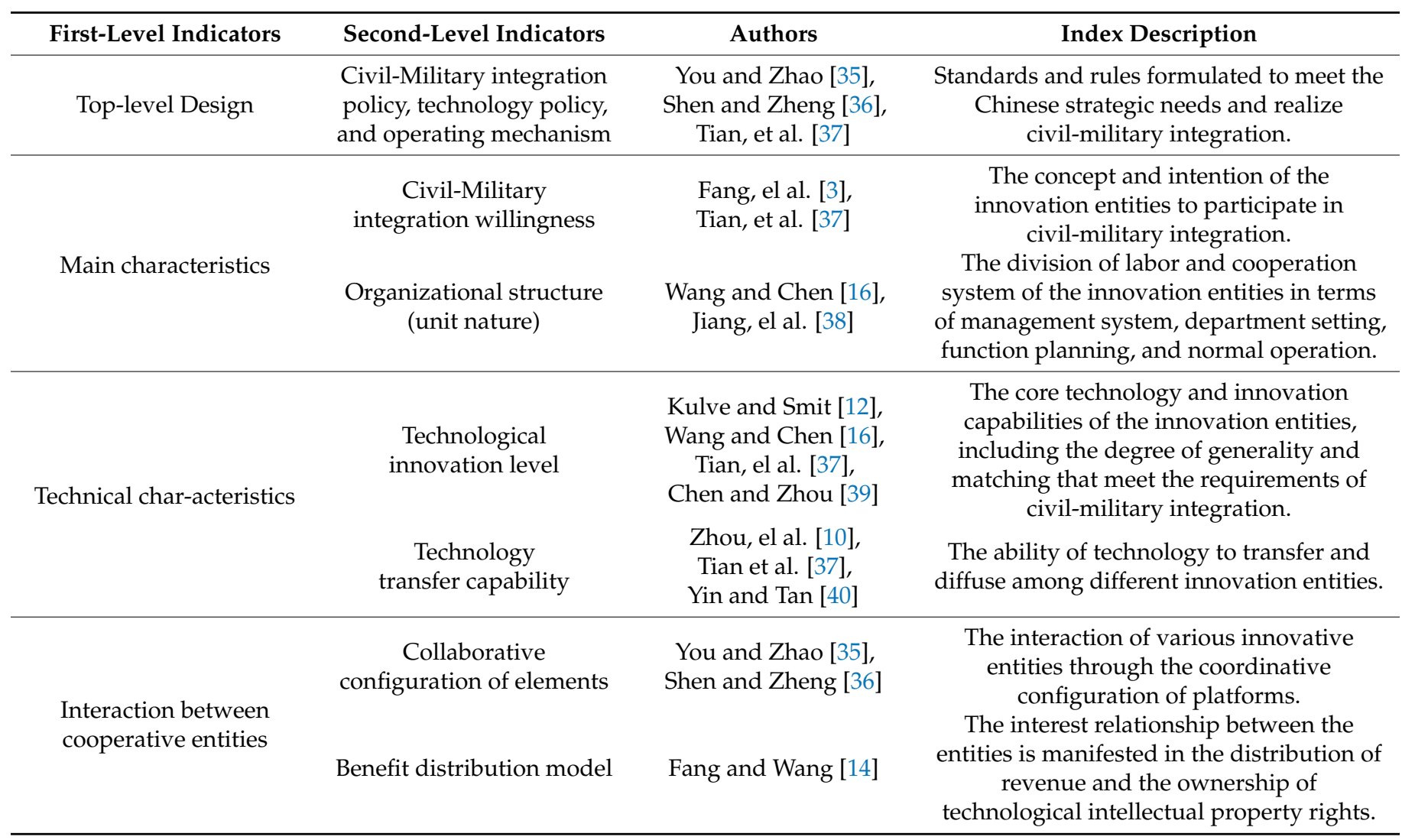




\subsection{Top-Level Design}

Innovation entities will formulate cooperation strategies based on the external environment, which is mainly top-level design of China. Specifically, it is China's support policy and operating mechanism for MCSTCI. The support policy for MCSTCI is a standard of conduct to meet the demands for technological innovation in the civil-military markets, with an eye to solving the high-precision technical problems and achieving the integration of military-civilian technology. The operating mechanism is the criteria and method by which the MCSTI entities can form cooperative relationships in accordance with relevant management systems and regulations, including the access mechanism, confidentiality mechanism, sharing mechanism, reward and punishment mechanism, etc. The support policies for MCSTI determine the generation of the operating mechanism, and the operating mechanism provides guarantee for the implementation of relevant policies. Different innovation entities have different understandings of supporting policies and operating mechanism, which results in differences in the partners selection.

\subsection{Main Characteristics}

The characteristics of the entities include the willingness of civil-military integration and organizational structure (unit nature), which mainly reflect the quality of the entities' participation in collaborative innovation at the non-technical level. A strong willingness to civil-military integration is an important basis for the formation of cooperative innovation partnership. If military industrial units can abandon the backward management concepts left in period of planned economy system and actively introduce cooperation mechanisms, while private enterprises are also willing to use their technical advantages to devote themselves to national defense construction, then the strong willingness of both sides to integrate will promote the process of MCSTI. The organizational structure of the innovation entities is the division of labor and collaboration system in terms of management system, department setting, function planning and normal operation. Generally speaking, the organizational structures of enterprises, universities, and research institutes are different. If you add the distinction between military and civilian entities, the differences will be even greater. In this way, the difference in organizational structure will increase the difficulty of communication and docking between innovation entities, and will also affect the stability of cooperative relationships. Therefore, the more reasonable the management system and the clearer the division of responsibilities, the easier it is to be selected as partners.

\subsection{Technical Characteristics}

Technological characteristics are the core of the entities' innovation capability, including the level of technological innovation and technology transfer capability. The technological innovation level of the entities is reflected in the degree of technological innovation, technological versatility, technological matching, and technological absorption ability. Generally speaking, universities and research institutes share knowledge innovation, basic research, applied research, and key technology research, while military industrial enterprises and private enterprises undertake both R\&D tasks and produce products that obtain economic benefits. In this way, the technological innovation level of any one entity represents its own core competitiveness and affects the overall effect of the collaborative innovation system. Technology transfer capability refers to the mutual influence, mutual penetration, mutual absorption, and benefit from the technology of each innovation entity. The technology transfer between entities can be divided into the stages of de-embedding, absorption, and embedding, and how to implement effective technology integration after technology embedding is the key to the cooperation of innovation entities. Therefore, strong technology transfer capability of each entity is the basis for achieving complementary advantages, mutual coordination, and benign interaction among innovation entities, and it is also a necessary quality for promoting the level of MCSTI. 


\subsection{Interaction between Cooperative Entities}

The interaction between cooperative entities has an important impact on the effect of MCSTI, mainly including the coordinative configuration of elements and benefit distribution model. Resource elements include funds, technology, talents, information, infrastructure, etc. The platform built by the government and intermediaries exchanges and shares information on supply and demand of military and civilian science and technology, strengthens the connection between military and civilian entities, so as to integrate the scientific and technological foundations, property rights, system, innovation atmosphere of both military and civilian entities, and accelerates the formation of a virtuous cycle of symbiotic interaction, which is the meaning of synergistic allocation of elements. The benefit distribution model is an important basis for maintaining the partnership of innovation entities. In the context of China's national strategy and socialist market economy, collaborative innovation is not based on cooperation at the expense of the interests of military (civilian) innovation entities, but on a reasonable and fair benefit distribution model to promote the benefits of all parties and maintain a long and efficient partnership, thus achieving a win-win situation for the state, the military, and society. To sum up, in the process of partner selection, we should fully consider the coordinative configuration of elements and benefit distribution model between ourselves and the candidates to be selected, so as to achieve good interaction between the two sides.

\section{Model Building}

The fuzzy multi-attribute decision-making process for the selection of MCSTCI partners includes three steps: firstly, to determine the index weights; secondly, to assemble the evaluation matrix given by each expert; thirdly, to select the appropriate decision-making method to rank the partners. In this model, it is assumed that there are $m$ candidate enterprises as $H=\left\{h_{1}, h_{2}, \cdots, h_{m}\right\}, n$ evaluation indicators as $G=\left\{g_{1}, g_{2}, \cdots, g_{n}\right\}$ and $l$ experts as $E=\left\{e_{1}, e_{2}, \cdots, e_{l}\right\}$. The evaluation value of expert $e_{k}(k=1,2 \cdots, l)$ for candidate enterprises $h_{i}(i=1,2 \cdots, m)$ about evaluation index $g_{j}(j=1,2 \cdots, n)$ is the interval intuitionistic fuzzy number, denoted as $r_{i j}^{k}=\left(\left[a_{i j}^{k}, b_{i j}^{k}\right],\left[c_{i j}^{k}, d_{i j}^{k}\right]\right)$, where $\left[a_{i j}^{k}, b_{i j}^{k}\right]$ denotes the membership interval of the interval intuitionistic fuzzy number, $\left[c_{i j}^{k}, d_{i j}^{k}\right]$ denotes the non-membership interval, $\left[a_{i j}^{k}, b_{i j}^{k}\right] \subseteq[0,1]\left[c_{i j}^{k}, d_{i j}^{k}\right] \subseteq[0,1]$ and $b_{i j}^{k}+d_{i j}^{k} \leq 1$. The evaluation matrix of expert $e_{k}$ can be denoted as $R^{k}=\left(r_{i j}^{k}\right)_{m \times n}$. The evaluation matrix can be determined by hiring experts in the military and civilian fields for interviews or scoring.

\subsection{Determination of Index Weights}

In the evaluation process of MCSTCI partners, because of the difference in the degree of influence of each evaluation index on partner selection, it is necessary to determine the weight of each index. Usually the indicator weights need to meet two conditions, namely

$$
\sum_{j=1}^{n} \omega_{j}=1, \omega_{j} \geq \varepsilon(j=1,2, \cdots, n)
$$

where $\varepsilon$ is a sufficiently small positive number. In this way, the standardization condition of indicator weights can be written as $W_{0}=\left\{W \mid \sum_{j=1}^{n} \omega_{j}=1, \omega_{j} \geq \varepsilon, j=1,2, \cdots, n\right\}$, which means that the weight of each indicator is not 0 and the sum is 1 . The methods of determining indicator weights generally include subjective assignment method and objective assignment method. Among them, the subjective assignment method is based on decision makers' preferences and expertise to determine the weights, which is highly subjective and cannot be weighted scientifically and objectively. Therefore, based on the interval intuitionistic fuzzy evaluation value of experts, this research combines the improved scoring function and entropy weight method to objectively assign weights to each index. 
5.1.1. Improvement of Scoring Function Based on Accuracy Function and Interval Length For $r_{i j}^{k}=\left(\left[a_{i j}^{k}, b_{i j}^{k}\right],\left[c_{i j}^{k}, d_{i j}^{k}\right]\right)$, the scoring function can be expressed as

$$
S\left(r_{i j}^{k}\right)=\frac{a_{i j}^{k}+b_{i j}^{k}-c_{i j}^{k}-d_{i j}^{k}}{2} \in[-1,1]
$$

The accuracy function can be expressed as

$$
H\left(r_{i j}^{k}\right)=\frac{a_{i j}^{k}+b_{i j}^{k}+c_{i j}^{k}+d_{i j}^{k}}{2} \in[0,1]
$$

The interval length can be expressed as

$$
L\left(r_{i j}^{k}\right)=\frac{b_{i j}^{k}-a_{i j}^{k}+d_{i j}^{k}-c_{i j}^{k}}{2} \in\left[0, \frac{1}{2}\right]
$$

For the comparison of the size of multiple interval intuitionistic fuzzy numbers, it is not scientific to simply use the value of the scoring function, because the scoring function is only a comparison of the degree of membership and the degree of non-membership, and its size does not fully reflect the amount of information contained in a fuzzy number. For example, $r_{1}=([0.3,0.6],[0.1,0.3])$ and $r_{2}=([0.3,0.5],[0.1,0.2])$ are two interval intuitionistic fuzzy numbers, their scoring function values are both $0.25 . r_{1}$ 's accuracy function value is 0.55 , corresponding to the hesitation interval is $(0.1,0.6) ; r_{2}$ 's accuracy function value is 0.65 , corresponding to the hesitation interval is $(0.3,0.6) . r_{1}$ is more accurate and less hesitant than $r_{2}$, indicating that the higher the degree of certainty of the evaluation value given by experts, the more reliable the data. Another example is that $r_{3}=([0.4,0.5],[0.1,0.2])$ and $r_{4}=([0.2,0.7],[0.05,0.25])$ are two interval intuitionistic fuzzy numbers, and their scoring function values are both 0.3 , but the interval length of $r_{3}$ is smaller than that of $r_{4}$, and the data are more concentrated, indicating that the data of $r_{3}$ are more accurate. From these two examples, it can be seen that the accuracy function can reflect the degree of certainty of the expert's assignment. When the accuracy is greater, the hesitation is smaller, indicating that the expert is more confident. The interval length, on the other hand, reflects the degree of concentration of the evaluated values, and the smaller the interval length, the more concentrated the distribution of the data. Therefore, when comparing data quality, the values of scoring function, accuracy function, and interval length should be integrated. For an interval intuitionistic fuzzy number given by an expert, the larger the value of the scoring function and accuracy function, the smaller the interval length, which means that the more information it contains, the more accurate and reliable the data, and it should be given a higher weight. In summary, the improved scoring function is defined as follows.

Definition 7. Let $r_{i j}^{k}=\left(\left[a_{i j}^{k}, b_{i j}^{k}\right],\left[c_{i j}^{k}, d_{i j}^{k}\right]\right)$ be the interval intuitionistic fuzzy number, and call $\hat{S}\left(r_{i j}^{k}\right)$ the improved scoring function of $r_{i j}^{k}$.

$\hat{S}\left(r_{i j}^{k}\right)=S\left(r_{i j}^{k}\right)+\alpha H\left(r_{i j}^{k}\right)-\beta L\left(r_{i j}^{k}\right)=\frac{1+\alpha+\beta}{2} a_{i j}^{k}+\frac{1+\alpha-\beta}{2} b_{i j}^{k}+\frac{-1+\alpha+\beta}{2} c_{i j}^{k}+\frac{-1+\alpha-\beta}{2} d_{i j}^{k}$

Since the improved scoring function still takes the scoring function as the entity, the accuracy function and the interval length both act less than the scoring function and in decreasing order, so $\alpha, \beta \in\left(0, \frac{1}{2}\right]$ and $\beta<\alpha$. According to the definition of the improved scoring function, the following proposition can be put forward.

Proposition 1. (Boundedness) If the interval intuitionistic fuzzy number is $r_{i j}^{k}=\left(\left[a_{i j}^{k}, b_{i j}^{k}\right],\left[c_{i j}^{k}, d_{i j}^{k}\right]\right)$, then the improved scoring function $\hat{S}\left(r_{i j}^{k}\right)$ satisfies. 


$$
\begin{array}{ll}
\text { I. } & \alpha-1 \leq \hat{S}\left(r_{i j}^{k}\right) \leq \alpha+1 \\
\text { II. } & \hat{S}\left(r_{i j}^{k}\right)=\alpha+1 \Leftrightarrow r_{i j}^{k}=([1,1],[0,0]) \\
\text { III } & \hat{S}\left(r_{i j}^{k}\right)=\alpha-1 \Leftrightarrow r_{i j}^{k}=([0,0],[1,1])
\end{array}
$$

Proof. Because $\alpha, \beta \in\left(0, \frac{1}{2}\right]$ and $\beta<\alpha$, then $\frac{1+\alpha+\beta}{2}>0, \frac{1+\alpha-\beta}{2}>0, \frac{-1+\alpha+\beta}{2}<0$, $\frac{-1+\alpha-\beta}{2}<0$. It can be seen that the coefficients before $a_{i j}^{k}$ and $b_{i j}^{k}$ are greater than zero, and the coefficients before $c_{i j}^{k}$ and $d_{i j}^{k}$ are less than zero. When $a_{i j}^{k}$ and $b_{i j}^{k}$ are maximum $1, c_{i j}^{k}$ and $d_{i j}^{k}$ are minimum 0 , at which time $\hat{S}\left(r_{i j}^{k}\right)_{\max }=\frac{1+\alpha+\beta}{2}+\frac{1+\alpha-\beta}{2}=1+\alpha$; when $a_{i j}^{k}$ and $b_{i j}^{k}$ are minimum $0, c_{i j}^{k}$ and $d_{i j}^{k}$ are maximum 1 , at which time $\hat{S}\left(r_{i j}^{k}\right)_{\max }=\frac{-1+\alpha+\beta}{2}+\frac{-1+\alpha-\beta}{2}=\alpha-1$. Therefore, $\hat{S}\left(r_{i j}^{k}\right) \in[\alpha-1, \alpha+1]$ and when $r_{i j}^{k}=([1,1],[0,0]), \hat{S}\left(r_{i j}^{k}\right)=\alpha+1$; when $r_{i j}^{k}=([0,0],[1,1]), \hat{S}\left(r_{i j}^{k}\right)=\alpha-1$.

Proposition 2. (Monotonicity) The improved scoring function $\hat{S}\left(r_{i j}^{k}\right)$ strictly monotonically increases with respect to the membership boundaries $a_{i j}^{k}$ and $b_{i j}^{k}$, while strictly monotonically decreases with respect to the non-membership boundaries $c_{i j}^{k}$ and $d_{i j}^{k}$.

Proof . Because of $\alpha, \beta \in\left(0, \frac{1}{2}\right]$ and $\beta<\alpha$, take the partial derivatives of $a_{i j^{\prime}}^{k} b_{i j^{\prime}}^{k} c_{i j}^{k}$, and $d_{i j}^{k}$ respectively, we can get $\frac{\partial \hat{S}\left(r_{i j}^{k}\right)}{\partial a_{i j}^{k}}=\frac{1+\alpha+\beta}{2}>0, \frac{\partial \hat{S}\left(r_{i j}^{k}\right)}{\partial b_{i j}^{k}}=\frac{1+\alpha-\beta}{2}>0, \frac{\partial \hat{S}\left(r_{i j}^{k}\right)}{\partial c_{i j}^{k}}=\frac{-1+\alpha+\beta}{2}<0$, $\frac{\partial \hat{S}\left(r_{i j}^{k}\right)}{\partial d_{i j}^{k}}=\frac{-1+\alpha-\beta}{2}<0$.

Therefore, $\hat{S}\left(r_{i j}^{k}\right)$ is strictly monotonically increasing with respect to $a_{i j}^{k}$ and $b_{i j}^{k}$, and strictly monotonically decreasing with respect to $c_{i j}^{k}$ and $d_{i j}^{k}$.

Proposition 3. (Comparison rule) ${ }^{1} r_{i j}^{k}=\left(\left[{ }^{1} a_{i j}^{k}{ }^{1} b_{i j}^{k}\right],\left[{ }^{1} c_{i j j^{\prime}}^{k} d_{i j}^{k}\right]\right)$ and ${ }^{2} r_{i j}^{k}=\left(\left[{ }^{2} a_{i j}^{k}, b_{i j}^{k}\right],\left[{ }^{2} c_{i j}^{k}{ }^{2} d_{i j}^{k}\right]\right)$ are interval intuitionistic fuzzy numbers. If ${ }^{1} a_{i j}^{k}>{ }^{2} a_{i j}^{k}{ }^{1}{ }^{1} b_{i j}^{k}>{ }^{2} b_{i j}^{k}$ and ${ }^{1} c_{i j}^{k}<{ }^{2} c_{i j}^{k}{ }^{1} d_{i j}^{k}<{ }^{2} d_{i j}^{k}$ then there is $\hat{S}\left({ }^{1} r_{i j}^{k}\right)>\hat{S}\left({ }^{2} r_{i j}^{k}\right)$.

Proof . The scoring function of the intuitionistic fuzzy numbers of the two intervals can be subtracted to obtain.

$\hat{S}\left({ }^{1} r_{i j}^{k}\right)-\hat{S}\left({ }^{2} r_{i j}^{k}\right)=\frac{1+\alpha+\beta}{2}\left({ }^{1} a_{i j}^{k}-{ }^{2} a_{i j}^{k}\right)+\frac{1+\alpha-\beta}{2}\left({ }^{1} b_{i j}^{k}-{ }^{2} b_{i j}^{k}\right)+\frac{-1+\alpha+\beta}{2}\left({ }^{1} c_{i j}^{k}-{ }^{2} c_{i j}^{k}\right)+\frac{-1+\alpha-\beta}{2}\left({ }^{1} d_{i j}^{k}-{ }^{2} d_{i j}^{k}\right)$

Since $\frac{1+\alpha+\beta}{2}>0, \frac{1+\alpha-\beta}{2}>0, \frac{-1+\alpha+\beta}{2}<0, \frac{-1+\alpha-\beta}{2}<0$ and ${ }^{1} a_{i j}^{k}>{ }^{2} a_{i j}^{k}{ }^{1} b_{i j}^{k}>{ }^{2} b_{i j}^{k}$ ${ }^{1} c_{i j}^{k}<{ }^{2} c_{i j}^{k},{ }^{1} d_{i j}^{k}<{ }^{2} d_{i j}^{k}$, the above formula is greater than 0 , that is $\hat{S}\left({ }^{1} r_{i j}^{k}\right)>\hat{S}\left({ }^{2} r_{i j}^{k}\right)$.

In summary, the following definition can be proposed.

Definition 8. Let ${ }^{1} r_{i j}^{k}=\left(\left[{ }^{1} a_{i j}^{k},{ }^{1} b_{i j}^{k}\right],\left[{ }^{1} c_{i j}^{k}, 1 d_{i j}^{k}\right]\right)$ and ${ }^{2} r_{i j}^{k}=\left(\left[{ }^{2} a_{i j}^{k},{ }^{2} b_{i j}^{k}\right],\left[{ }^{2} c_{i j}^{k}{ }^{\prime} d_{i j}^{k}\right]\right)$ be interval intuitionistic fuzzy numbers, $\alpha, \beta \in\left(0, \frac{1}{2}\right]$ and $\beta<\alpha$, then

I. If $\hat{S}\left({ }^{1} r_{i j}^{k}\right)>\hat{S}\left({ }^{2} r_{i j}^{k}\right)$, then ${ }^{1} r_{i j}^{k}>{ }^{2} r_{i j}^{k}$

II. If $\hat{S}\left({ }^{1} r_{i j}^{k}\right)<\hat{S}\left({ }^{2} r_{i j}^{k}\right)$, then ${ }^{1} r_{i j}^{k}<{ }^{2} r_{i j}^{k}$ 
III. If $\hat{S}\left({ }^{1} r_{i j}^{k}\right)=\hat{S}\left({ }^{2} r_{i j}^{k}\right)$, then ${ }^{1} r_{i j}^{k} \sim{ }^{2} r_{i j}^{k}$

The improved scoring function more comprehensively reflects the information and reliability contained in an intuitionistic fuzzy number. The larger the value of $\hat{S}\left(r_{i j}^{k}\right)$, the higher the expert's understanding and grasp of the indicator, and the higher the weight should be given. Therefore, the entropy weighting method combined with the improved scoring function is applied next to determine the index weights.

\subsubsection{Entropy Weighting Theory to Determine Index Weights}

Entropy weighting theory is an objective weighting method, the basic idea of which is to determine the objective weight according to the magnitude of the index variability. Generally speaking, if the information entropy of an indicator is smaller, it indicates that the amount of information provided by the indicator is greater, and the role it can play in the comprehensive evaluation is also greater, and it should be given a higher weight. On the contrary, if the information entropy of an indicator is larger, it indicates that the amount of information provided by the indicator is smaller, and the role it can play in the comprehensive evaluation is smaller, so it should be given a lower weight [41].

The information entropy of a set of data can be expressed as

$$
R=-\ln (n)^{-1} \sum_{i=1}^{n} p_{i j} \ln p_{i j}
$$

If $p_{i j}=0$, then define $\lim _{p_{i j} \rightarrow p} p_{i j} \ln p_{i j}=0$.

First, $\hat{S}\left(r_{i j}^{k}\right)$ is calculated from the interval intuitionistic fuzzy evaluation values given by the experts, the interval intuitionistic fuzzy matrix $R^{k}$ is transformed into a scoring function matrix $\hat{S}^{k}$, and the scoring function values within the matrix are normalized as follows.

$$
\widetilde{S}\left(r_{i j}^{k}\right)=\frac{\hat{S}\left(r_{i j}^{k}\right)-\min \hat{S}\left(r_{i j}^{k}\right)}{\max \hat{S}\left(r_{i j}^{k}\right)-\min \hat{S}\left(r_{i j}^{k}\right)}
$$

The next step is to normalize the above values:

$$
\widetilde{S}_{0}\left(r_{i j}^{k}\right)=\frac{\widetilde{S}\left(r_{i j}^{k}\right)}{\sum_{i=1}^{m} \widetilde{S}\left(r_{i j}^{k}\right)}
$$

Substituting Formula (15) into Formula (13), the average information entropy of indicator $\mathrm{g}$ can be obtained as:

$$
\widetilde{R}\left(g_{j}\right)=-\ln (n)^{-1} \sum_{i=1}^{m} \widetilde{S}_{0}\left(r_{i j}^{k}\right) \ln \widetilde{S}_{0}\left(r_{i j}^{k}\right)
$$

Therefore, the resulting information entropy vector for each indicator is $\widetilde{R}=\left(\widetilde{r}_{1}, \widetilde{r}_{2}, \cdots, \widetilde{r}_{n}\right)^{T}$, and the weights of each indicator is:

$$
\omega_{j}^{k}=\frac{1-\widetilde{R}\left(g_{j}\right)}{n-\sum_{j=1}^{n} \widetilde{R}\left(g_{j}\right)}
$$

\subsection{Considering Matrix Assembly and Transformation of Decision Makers' Risk Attitudes}

When the indicator weights are determined, the weight values should be combined with the interval intuitionistic fuzzy matrix. In the actual decision-making process, the 
decision maker's attitude toward risk often has a significant impact on the decision outcome. In order to fully consider the risk preferences of decision makers, an evaluation matrix transformation method based on hesitancy distribution is proposed to transform the interval intuitionistic fuzzy matrix into an intuitionistic fuzzy matrix, which lays the foundation for the subsequent decision-making process.

\subsubsection{Assembly of Expert Evaluation Matrix}

From the above, the evaluation matrix of expert $e_{k}$ is $R^{k}=\left(r_{i j}^{k}\right)_{m \times n^{\prime}}$, where $r_{i j}^{k}=\left(\left[a_{i j}^{k}, b_{i j}^{k}\right],\left[c_{i j}^{k}, d_{i j}^{k}\right]\right)$. According to the IIFWA operator and the interval intuitionistic fuzzy number algorithm, the single-person decision matrix $R^{k}=\left(r_{i j}^{k}\right)_{m \times n}$ of $l$ experts can be assembled into a comprehensive decision matrix $R=\left(r_{i j}\right)_{m \times n^{\prime}}$, where each element is $r_{i j}=\left(\left[a_{i j}, b_{i j}\right],\left[c_{i j}, d_{i j}\right]\right)$ can be specifically obtained from the following Equation.

$$
r_{i j}=\sum_{k=1}^{l} \omega_{j}^{k} r_{i j}^{k}=\left(\left[\sum_{k=1}^{l} \omega_{j}^{k} a_{i j}^{k}, \sum_{k=1}^{l} \omega_{j}^{k} b_{i j}^{k}\right],\left[\sum_{k=1}^{l} \omega_{j}^{k} c_{i j}^{k}, \sum_{k=1}^{l} \omega_{j}^{k} d_{i j}^{k}\right]\right)=\left(\left[1-\prod_{k=1}^{l}\left(1-a_{i j}^{k}\right)^{\omega_{j}^{k}}, 1-\prod_{k=1}^{l}\left(1-b_{i j}^{k}\right)^{\omega_{j}^{k}}\right],\left[\prod_{k=1}^{l}\left(c_{i j}^{k}\right)^{\omega_{j}^{k}}, \prod_{k=1}^{l}\left(d_{i j}^{k}\right)^{\omega_{j}^{k}}\right]\right)
$$

It can be seen that $R=\left(r_{i j}\right)_{m \times n}$ is still an interval intuitionistic fuzzy matrix.

\subsubsection{Matrix Transformation Based on Hesitancy Distribution}

There are often three risk attitudes of a decision maker, namely risk-seeking, riskneutral, and risk-averse. For the same degree of risk, different decision makers make different choices: risk-seekers are keen to take risks and speculate; risk-neutral people do not differentiate between jobs with the same expected return; risk-averse people prefer more certain projects with the same expected return [42]. Regarding the selection of MCSTCI partners, due to the large number and different levels of potential suppliers, the risk-seeking decision makers are more optimistic and inclined to believe in a larger degree of membership for the evaluation values given by experts, which are prone to get higher evaluation values; while the risk-averse decision makers are more cautious and attach more importance to the non-affiliation values, which are prone to get lower evaluation values. Therefore, the risk preference coefficient $\theta(0 \leq \theta \leq 1)$ is introduced to distinguish the influence of different risk attitudes of decision makers. After the expert's single-person decision matrix $R^{k}=\left(r_{i j}^{k}\right)_{m \times n}$ is assembled into a comprehensive decision matrix, $R=\left(r_{i j}\right)_{m \times n}$ for each element $r_{i j}=\left(\left[a_{i j}, b_{i j}\right],\left[c_{i j}, d_{i j}\right]\right)$, let

$$
\begin{aligned}
& u_{i j}=a_{i j}+\theta\left(b_{i j}-a_{i j}\right)=(1-\theta) a_{i j}+\theta b_{i j} \\
& v_{i j}=d_{i j}-\theta\left(d_{i j}-c_{i j}\right)=\theta c_{i j}+(1-\theta) d_{i j}
\end{aligned}
$$

Among them, $\theta$ is the risk preference coefficient. When $0 \leq \theta<\frac{1}{2}$, the decision maker holds risk averse attitude, then $u_{i j}$ takes the value less than the median of the interval, $v_{i j}$ takes the value greater than the median of the interval; when $\theta=\frac{1}{2}$, the decision maker holds risk-neutral attitude, then $u_{i j}$ takes the value equal to the median of the interval, $v_{i j}$ takes the value equal to the median of the interval; when $\frac{1}{2}<\theta \leq 1$, the decision maker holds risk seeking attitude, then $u_{i j}$ takes the value greater than the median of the interval, $v_{i j}$ takes the value less than the median of the interval. In this way, by adjusting the risk preference coefficient $\theta$, the evaluation values obtained by decision makers with different risk attitudes can be obtained. At this time, the interval intuitionistic fuzzy number $r_{i j}=\left(\left[a_{i j}, b_{i j}\right],\left[c_{i j}, d_{i j}\right]\right)$ is transformed into intuitionistic fuzzy number $t_{i j}=\left(u_{i j}, v_{i j}\right)$, and the interval intuitionistic fuzzy matrix $R=\left(r_{i j}\right)_{m \times n}$ is transformed into intuitionistic fuzzy matrix $T=\left(t_{i j}\right)_{m \times n}$.

However, an intuitionistic fuzzy number may have a large hesitancy degree, and the influence of hesitancy degree on the evaluation value cannot be captured by Equations (19) and (20) 
alone. The presence of hesitation means that the expert cannot determine whether this part of the value belongs to the membership or non-membership degree; in other words, if the expert has complete information, then this part of the value should be divided between the membership and non-membership degrees. Therefore, in the case of incomplete information, the decision maker can assign the hesitancy degree according to his own risk preference. In the following, the hesitancy degree is assigned by the risk preference coefficient $\theta$ such that

$$
\begin{gathered}
\widetilde{u}_{i j}=(1-\theta) a_{i j}+\theta b_{i j}+\theta \pi_{i j} \\
\widetilde{v}_{i j}=\theta c_{i j}+(1-\theta) d_{i j}+(1-\theta) \pi_{i j}
\end{gathered}
$$

Among them

$$
\widetilde{\pi}_{i j}=1-u_{i j}-v_{i j}=1-(1-\theta) a_{i j}-\theta b_{i j}-\theta c_{i j}-(1-\theta) d_{i j}
$$

When $0 \leq \theta<\frac{1}{2}$, the hesitancy degree is more assigned to the non-membership degree, and less to the membership degree, indicating that the decision-maker has risk aversion attitude; when $\theta=\frac{1}{2}$, the hesitancy degree is assigned to membership degrees and non-membership degrees to the same extent, indicating that the decision-maker has riskneutral attitude; when $\frac{1}{2}<\theta \leq 1$, the hesitancy degree is more assigned to the membership degree, and less to the non-membership degree, indicating that the decision-maker has riskseeking attitude. In particular, when $\theta=0$, the decision maker is completely risk-averse, where not only the membership degree takes the minimum of the interval intuitionistic fuzzy number, but also the non-membership degree takes the maximum of the interval intuitionistic fuzzy number, and the hesitancy degree is completely assigned to the nonmembership degree; when $\theta=1$, the decision maker is completely risk-seeking, where not only the membership degree takes the maximum of the interval intuitionistic fuzzy number, but also the non-membership degree takes the minimum of the interval intuitionistic fuzzy number, and the hesitancy degree is completely assigned to the membership degree. In this way, the intuitionistic fuzzy number $t_{i j}=\left(u_{i j}, v_{i j}\right)$ is transformed into $\widetilde{t}_{i j}=\left(\widetilde{u}_{i j}, \widetilde{v}_{i j}\right)$ and the intuitionistic fuzzy matrix $T=\left(t_{i j}\right)_{m \times n}$ is transformed into $\widetilde{T}=\left(\widetilde{t}_{i j}\right)_{m \times n}$. In particular, the hesitancy degree $\widetilde{\pi}_{i j}$ of each element $\widetilde{t}_{i j}$ in the intuitionistic fuzzy matrix $\widetilde{T}=\left(\widetilde{t}_{i j}\right)_{m \times n}$ is zero.

\subsubsection{Decision-Making Process Based on Grey Correlation Analysis and the TOPSIS} Method

The TOPSIS method is a multi-objective comprehensive decision-making method by constructing positive and negative ideal solution benchmarks, which is widely used by scholars. However, there are two limitations: one is that the differences between the evaluation indexes within the solution and the ideal solution cannot be reflected; the other is that the superiority ranking is performed by calculating the Euclidean distance, but the ranking of two solutions cannot be performed if the relative closeness of two solutions is the same. And grey correlation analysis can clarify the relation between the elements to achieve the optimal solution. Correlation integral analysis focuses on the expression and closeness of the correlation between two variables; grey correlation analysis focuses on the quantification and ordering of the correlation. For this reason, grey correlation analysis is considered for this study.

The limitation is that the grey correlation degree can only reflect the similarity of the geometric shape of the data curve of the solution. Therefore, it is planned to combine the grey correlation analysis method and the TOPSIS method to construct a new grey ideal value approximation model. Combining these two methods can obtain the degree of deviation between the candidate partners and the positive and negative ideal values, as well as the changes in the evaluation index elements of the candidate partners, which makes the selection of partners more scientific and reasonable. 
Step 1: Determining the positive ideal solution and negative ideal solution. Since the evaluation indicators in this paper are all benefit-type indicators, this is, the larger the value of the index means the better the evaluation result. There is no need to standardize the evaluation values. For each element $\widetilde{t}_{i j}=\left(\widetilde{u}_{i j}, \widetilde{v}_{i j}\right)$ in the intuitionistic fuzzy matrix $\widetilde{T}=\left(\widetilde{t}_{i j}\right)_{m \times n^{\prime}}$ the positive ideal solution takes the most satisfactory value $F^{+}=\left(f_{1}^{+}, f_{2}^{+}, \cdots, f_{n}^{+}\right)$of all the evaluated objects. Among them,

$$
f_{j}^{+}=\max _{1 \leq i \leq m} \widetilde{t}_{i j}=\left(\widetilde{u}_{j}^{+}, \widetilde{v}_{j}^{+}\right)=\left(\max _{1 \leq i \leq m} \widetilde{u}_{i j}, \min _{1 \leq i \leq m} \widetilde{v}_{i j}\right)
$$

The negative ideal solution takes the least satisfactory value $F^{-}=\left(f_{1}^{-}, f_{2}^{-}, \cdots, f_{n}^{-}\right)$ of all evaluated objects. Among them,

$$
f_{j}^{-}=\min _{1 \leq i \leq m} \widetilde{i}_{i j}=\left(\widetilde{u}_{j}^{-}, \widetilde{v}_{j}^{-}\right)=\left(\min _{1 \leq i \leq m} \widetilde{u}_{i j}, \max _{1 \leq i \leq m} \widetilde{v}_{i j}\right)
$$

Because of the hesitancy $\widetilde{\pi}_{i j}=0$ of the weighted intuitionistic fuzzy evaluation matrix $\widetilde{T}=\left(\widetilde{t}_{i j}\right)_{m \times n^{\prime}}$ it is guaranteed that $\widetilde{v}_{i j}$ takes the minimum value when $\widetilde{u}_{i j}$ takes the maximum value above and that $\widetilde{v}_{i j}$ takes the maximum value when $\widetilde{u}_{i j}$ takes the minimum value.

Step 2: Calculating the Euclidean distance between each candidate partner and the positive and negative ideal solutions.

The distance to the positive ideal solution is

$$
d_{i}^{+}=\sum_{j=1}^{n} d\left(\widetilde{t}_{i j}, f_{i}^{+}\right)=\sqrt{\frac{1}{2 n} \sum_{j=1}^{n}\left[\left(\widetilde{u}_{i j}-\widetilde{u}_{j}^{+}\right)^{2}+\left(\widetilde{v}_{i j}-\widetilde{v}_{j}^{+}\right)^{2}\right]}
$$

The distance to the virtual worst solution is

$$
d_{i}^{-}=\sum_{j=1}^{n} d\left(\widetilde{t}_{i j}, f_{i}^{-}\right)=\sqrt{\frac{1}{2 n} \sum_{j=1}^{n}\left[\left(\widetilde{u}_{i j}-\widetilde{u}_{j}^{-}\right)^{2}+\left(\widetilde{v}_{i j}-\widetilde{v}_{j}^{-}\right)^{2}\right]}
$$

Since the hesitation degree of each intuitionistic fuzzy number is zero, the above formula omits the hesitation degree.

Step 3: Calculating the grey correlation degree between each candidate partner and the positive and negative ideal solutions.

The gray correlation matrix between the candidate partner and the positive ideal solution is $\mathrm{O}^{+}=\left(o_{i j}^{+}\right)_{m \times n^{\prime}}$, where

$$
o_{i j}^{+}=\frac{\min _{1 \leq i \leq m 1 \leq j \leq n} \min _{1}\left|f_{j}^{+}-\widetilde{t}_{i j}\right|+\rho \max _{1 \leq i \leq m 1 \leq j \leq n}\left|f_{j}^{+}-\widetilde{t}_{i j}\right|}{\left|f_{j}^{+}-\widetilde{t}_{i j}\right|+\rho \max _{1 \leq i \leq m 1 \leq j \leq n} \max _{1}\left|f_{j}^{+}-\widetilde{t}_{i j}\right|}
$$

The gray correlation matrix between the candidate partner and the negative ideal solution is $O^{-}=\left(o_{i j}^{-}\right)_{m \times n^{\prime}}$, where

$$
o_{i j}^{-}=\frac{\min _{1 \leq i \leq m 1 \leq j \leq n} \min _{1}\left|f_{j}^{-}-\widetilde{t}_{i j}\right|+\rho \max _{1 \leq i \leq m 1 \leq j \leq n}\left|f_{j}^{-}-\widetilde{t}_{i j}\right|}{\left|f_{j}^{-}-\widetilde{t}_{i j}\right|+\rho \max _{1 \leq i \leq m 1 \leq j \leq n} \max _{j}\left|f_{j}^{-}-\widetilde{t}_{i j}\right|}
$$

Among them, $\rho \in[0,1]$ is the resolution coefficient, generally $\rho=0.5$. 
The gray correlation degree between the candidate partner and the positive ideal solution is

$$
o_{i}^{+}=\frac{1}{n} \sum_{j=1}^{n} o_{i j}^{+}
$$

The gray correlation degree between the candidate partner and the negative ideal solution is

$$
o_{i}^{-}=\frac{1}{n} \sum_{j=1}^{n} o_{i j}^{-}
$$

Step 4: Dimensionless processing of Euclidean distance and gray correlation degree. Since Euclidean distance and gray correlation degree have different units of measurement, dimensionless processing is required.

$$
\begin{aligned}
& D_{i}^{+}=\frac{d_{i}^{+}}{\max _{1 \leq i \leq m} d_{i}^{+}} \\
& D_{i}^{-}=\frac{d_{i}^{-}}{\max _{1 \leq i \leq m} d_{i}^{-}} \\
& O_{i}^{+}=\frac{o_{i}^{+}}{\max _{1 \leq i \leq m} o_{i}^{+}} \\
& O_{i}^{-}=\frac{o_{i}^{-}}{\max _{1 \leq i \leq m} o_{i}^{-}}
\end{aligned}
$$

Step 5: Calculating the comprehensive closeness of each candidate partner. Since $D_{i}^{+}$and $D_{i}^{-}$respectively represent the distance between each candidate partner and the positive and negative ideal solutions, while $\mathrm{O}_{i}^{+}$and $\mathrm{O}_{i}^{-}$respectively represent the closeness between each candidate partner and the positive and negative ideal solutions. Therefore, the larger the values of $D_{i}^{-}$and $O_{i}^{+}$, the closer the candidate partners are to the positive ideal solution; the larger the values of $D_{i}^{+}$and $O_{i}^{-}$, the closer the candidate partners are to the negative ideal solution. To reflect this difference, let

$$
\begin{aligned}
X_{i}^{+} & =\frac{D_{i}^{-}}{D_{i}^{+}+D_{i}^{-}} \\
Y_{i}^{+} & =\frac{O_{i}^{+}}{O_{i}^{+}+O_{i}^{-}}
\end{aligned}
$$

It can be seen that the greater the value of $D_{i}^{-}$, the greater the value of $X_{i}^{+}$; the greater the value of $\mathrm{O}_{i}^{+}$, the greater the value of $Y_{i}^{+}$. Combining the distance dimension with the correlation dimension, the comprehensive closeness of the candidate partners can be obtained.

$$
Z_{i}^{+}=\xi X_{i}^{+}+\eta Y_{i}^{+}
$$

Among them, $\xi$ and $\eta$ are the degree of decision maker's preference for location and shape, $\xi \eta \in[0,1]$ and $\xi+\eta=1$, the decision maker can determine their values according to their preferences. Rank the candidate partners according to the degree of comprehensive closeness. The greater the closeness, the better the subject, and vice versa.

\section{Numerical Examples}

Suppose that a military equipment manufacturing enterprise in Beijing conducts research and development on a certain anti-ship missile weapon, and needs to seek civilian high-tech enterprises to carry out joint technical research due to technical obstacles. 
Through the preliminary review, five private enterprises $h_{1}, h_{2}, h_{3}, h_{4}, h_{5}$ are identified as candidates for cooperation partners. Enterprise decision makers engaged five experts in the field of civil-military integration and equipment development $e_{1}, e_{2}, e_{3}, e_{4}, e_{5}$ to evaluate the cooperation qualifications of the five units. These five experts are the deputy director of the Strategic Planning Bureau of the Office of the Central Civil-Military Integration Development Committee, the professor of the Civil-Military Integration Development Research Center of China People's Liberation Army National Defense University, the professor of Beijing Institute of Technology, the researcher of the 714th Research Institute of China Shipbuilding Industry Group Co., Ltd., and the engineer of Leike Defense Technology Co., Ltd., representing five types of entities from government departments, military academy, colleges and universities, research institutions, and private enterprises. The indicators of qualification evaluation include the policy and operation mechanism of MCSTCI $g_{1}$, the willingness of civil-military integration $g_{2}$, the organizational structure (unit nature) $g_{3}$, the level of technological innovation $g_{4}$, the technology transfer capability $g_{5}$, the coordinative configuration of elements $g_{6}$ and the benefit distribution model $g_{7}$, which are the seven judging criteria. Therefore, $m=5, n=7, l=5$. The experts' evaluation of the qualification of selected objects is expressed by the interval intuitionistic fuzzy numbers, where the membership degree interval represents the extent to which experts think the candidate object meets the requirements of the index, and the non-membership interval represents the extent to which experts think the candidate object doesn't meet the requirements of the index. The original evaluation values given by each expert are shown in Table 2.

According to the expert evaluation data in Table 2, combined with the improved scoring function and entropy weight method proposed in Equations (9)-(17), taking $\alpha=0.5$ and $\beta=0.25$, the weight value of each expert on each index can be obtained, as shown in Table 3.

Table 2. Expert evaluation table for selection of MCSTCI partners.

\begin{tabular}{|c|c|c|c|c|c|c|c|c|}
\hline & & $g_{1}$ & $g_{2}$ & $g_{3}$ & $g_{4}$ & $g_{5}$ & $g_{6}$ & $g_{7}$ \\
\hline \multirow{5}{*}{$r^{1}$} & $h_{1}$ & $\begin{array}{l}{[0.62,0.71]} \\
{[0.13,0.21]}\end{array}$ & $\begin{array}{l}{[0.51,0.73]} \\
{[0.16,0.21]}\end{array}$ & $\begin{array}{l}{[0.59,0.86]} \\
{[0.06,0.10]}\end{array}$ & $\begin{array}{l}{[0.16,0.46],} \\
{[0.41,0.53]}\end{array}$ & $\begin{array}{l}{[0.14,0.28]} \\
{[0.47,0.66]}\end{array}$ & $\begin{array}{l}{[0.25,0.45]} \\
{[0.46,0.53]}\end{array}$ & $\begin{array}{l}{[0.63,0.96],} \\
{[0.02,0.04]}\end{array}$ \\
\hline & $h_{2}$ & $\begin{array}{l}{[0.50,0.83]} \\
{[0.11,0.15]}\end{array}$ & $\begin{array}{l}{[0.45,0.66]} \\
{[0.12,0.23]}\end{array}$ & $\begin{array}{l}{[0.66,0.72]} \\
{[0.14,0.21]}\end{array}$ & $\begin{array}{l}{[0.21,0.36],} \\
{[0.46,0.58]}\end{array}$ & $\begin{array}{l}{[0.31,0.51]} \\
{[0.14,0.31]}\end{array}$ & $\begin{array}{l}{[0.51,0.57]} \\
{[0.21,0.31]}\end{array}$ & $\begin{array}{l}{[0.12,0.46],} \\
{[0.23,0.43]}\end{array}$ \\
\hline & $h_{3}$ & $\begin{array}{l}{[0.72,0.82]} \\
{[0.05,0.16]}\end{array}$ & $\begin{array}{l}{[0.41,0.81]} \\
{[0.11,0.18]}\end{array}$ & $\begin{array}{l}{[0.36,0.51]} \\
{[0.26,0.36]}\end{array}$ & $\begin{array}{l}{[0.11,0.38],} \\
{[0.56,0.60]}\end{array}$ & $\begin{array}{l}{[0.13,0.56]} \\
{[0.26,0.43]}\end{array}$ & $\begin{array}{l}{[0.16,0.56]} \\
{[0.21,0.42]}\end{array}$ & $\begin{array}{l}{[0.55,0.90],} \\
{[0.02,0.05]}\end{array}$ \\
\hline & $h_{4}$ & $\begin{array}{l}{[0.59,0.85]} \\
{[0.07,0.12]}\end{array}$ & $\begin{array}{l}{[0.62,0.78]} \\
{[0.14,0.20]}\end{array}$ & $\begin{array}{l}{[0.41,0.76]} \\
{[0.11,0.18]}\end{array}$ & $\begin{array}{l}{[0.21,0.33],} \\
{[0.44,0.57]}\end{array}$ & $\begin{array}{l}{[0.21,0.54]} \\
{[0.07,0.36]}\end{array}$ & $\begin{array}{l}{[0.26,0.46]} \\
{[0.14,0.21]}\end{array}$ & $\begin{array}{l}{[0.40,0.75],} \\
{[0.10,0.15]}\end{array}$ \\
\hline & $h_{5}$ & $\begin{array}{l}{[0.73,0.89]} \\
{[0.06,0.09]}\end{array}$ & $\begin{array}{l}{[0.43,0.55]} \\
{[0.27,0.38]}\end{array}$ & $\begin{array}{l}{[0.36,0.61]} \\
{[0.03,0.11]}\end{array}$ & $\begin{array}{l}{[0.08,0.21],} \\
{[0.31,0.56]}\end{array}$ & $\begin{array}{l}{[0.20,0.42]} \\
{[0.36,0.56]}\end{array}$ & $\begin{array}{l}{[0.51,0.81]} \\
{[0.12,0.18]}\end{array}$ & $\begin{array}{l}{[0.34,0.55],} \\
{[0.22,0.45]}\end{array}$ \\
\hline \multirow{5}{*}{$r^{2}$} & $h_{1}$ & $\begin{array}{l}{[0.40,0.72]} \\
{[0.10,0.15]}\end{array}$ & $\begin{array}{l}{[0.10,0.42]} \\
{[0.33,0.58]}\end{array}$ & $\begin{array}{l}{[0.13,0.25]} \\
{[0.54,0.70]}\end{array}$ & $\begin{array}{l}{[0.12,0.34],} \\
{[0.40,0.60]}\end{array}$ & $\begin{array}{l}{[0.74,0.85]} \\
{[0.10,0.15]}\end{array}$ & $\begin{array}{l}{[0.13,0.58]} \\
{[0.27,0.42]}\end{array}$ & $\begin{array}{l}{[0.46,0.67],} \\
{[0.15,0.25]}\end{array}$ \\
\hline & $h_{2}$ & $\begin{array}{l}{[0.55,0.65]} \\
{[0.07,0.15]}\end{array}$ & $\begin{array}{c}{[0.37,0.39]} \\
{[0.51,0.61]}\end{array}$ & $\begin{array}{l}{[0.57,0.90]} \\
{[0.02,0.05]}\end{array}$ & $\begin{array}{l}{[0.05,0.36],} \\
{[0.17,0.42]}\end{array}$ & $\begin{array}{l}{[0.35,0.60]} \\
{[0.10,0.25]}\end{array}$ & $\begin{array}{l}{[0.16,0.32]} \\
{[0.27,0.47]}\end{array}$ & $\begin{array}{l}{[0.26,0.31],} \\
{[0.12,0.16]}\end{array}$ \\
\hline & $h_{3}$ & $\begin{array}{l}{[0.43,0.88]} \\
{[0.06,0.12]}\end{array}$ & $\begin{array}{l}{[0.41,0.75]} \\
{[0.08,0.15]}\end{array}$ & $\begin{array}{l}{[0.35,0.47]} \\
{[0.12,0.48]}\end{array}$ & $\begin{array}{l}{[0.12,0.45],} \\
{[0.26,0.50]}\end{array}$ & $\begin{array}{l}{[0.20,0.52]} \\
{[0.15,0.25]}\end{array}$ & $\begin{array}{l}{[0.41,0.66]} \\
{[0.13,0.22]}\end{array}$ & $\begin{array}{l}{[0.35,0.45],} \\
{[0.16,0.25]}\end{array}$ \\
\hline & $h_{4}$ & $\begin{array}{l}{[0.70,0.88]} \\
{[0.05,0.12]}\end{array}$ & $\begin{array}{l}{[0.10,0.42]} \\
{[0.43,0.65]}\end{array}$ & $\begin{array}{l}{[0.25,0.46]} \\
{[0.13,0.15]}\end{array}$ & $\begin{array}{l}{[0.20,0.34],} \\
{[0.10,0.15]}\end{array}$ & $\begin{array}{l}{[0.09,0.14]} \\
{[0.36,0.42]}\end{array}$ & $\begin{array}{l}{[0.44,0.71]} \\
{[0.15,0.27]}\end{array}$ & $\begin{array}{l}{[0.10,0.35],} \\
{[0.55,0.61]}\end{array}$ \\
\hline & $h_{5}$ & $\begin{array}{l}{[0.30,0.54]} \\
{[0.10,0.15]}\end{array}$ & $\begin{array}{l}{[0.34,0.54]} \\
{[0.22,0.42]}\end{array}$ & $\begin{array}{l}{[0.60,0.81]} \\
{[0.02,0.10]}\end{array}$ & $\begin{array}{l}{[0.40,0.81],} \\
{[0.06,0.16]}\end{array}$ & $\begin{array}{l}{[0.74,0.92]} \\
{[0.01,0.06]}\end{array}$ & $\begin{array}{l}{[0.13,0.25]} \\
{[0.35,0.50]}\end{array}$ & $\begin{array}{l}{[0.26,0.34],} \\
{[0.51,0.52]}\end{array}$ \\
\hline
\end{tabular}


Table 2. Cont.

\begin{tabular}{|c|c|c|c|c|c|c|c|c|}
\hline & & $g_{1}$ & $g_{2}$ & $g_{3}$ & $g_{4}$ & $g_{5}$ & $g_{6}$ & $g_{7}$ \\
\hline \multirow{5}{*}{$r^{3}$} & $h_{1}$ & $\begin{array}{l}{[0.41,0.66]} \\
{[0.21,0.31]}\end{array}$ & $\begin{array}{l}{[0.45,0.72],} \\
{[0.06,0.14]}\end{array}$ & $\begin{array}{l}{[0.74,0.83],} \\
{[0.01,0.02]}\end{array}$ & $\begin{array}{l}{[0.11,0.46]} \\
{[0.25,0.29]}\end{array}$ & $\begin{array}{l}{[0.21,0.36]} \\
{[0.05,0.27]}\end{array}$ & $\begin{array}{l}{[0.21,0.25]} \\
{[0.41,0.43]}\end{array}$ & $\begin{array}{l}{[0.72,0.82],} \\
{[0.03,0.12]}\end{array}$ \\
\hline & $h_{2}$ & $\begin{array}{l}{[0.16,0.56]} \\
{[0.30,0.37]}\end{array}$ & $\begin{array}{l}{[0.28,0.45],} \\
{[0.12,0.33]}\end{array}$ & $\begin{array}{l}{[0.35,0.42],} \\
{[0.12,0.21]}\end{array}$ & $\begin{array}{l}{[0.36,0.55]} \\
{[0.24,0.35]}\end{array}$ & $\begin{array}{l}{[0.11,0.23]} \\
{[0.35,0.42]}\end{array}$ & $\begin{array}{l}{[0.33,0.46]} \\
{[0.12,0.19]}\end{array}$ & $\begin{array}{l}{[0.21,0.44],} \\
{[0.05,0.26]}\end{array}$ \\
\hline & $h_{3}$ & $\begin{array}{l}{[0.66,0.71]} \\
{[0.20,0.26]}\end{array}$ & $\begin{array}{l}{[0.46,0.81],} \\
{[0.15,0.19]}\end{array}$ & $\begin{array}{l}{[0.22,0.48],} \\
{[0.41,0.45]}\end{array}$ & $\begin{array}{l}{[0.50,0.61]} \\
{[0.11,0.14]}\end{array}$ & $\begin{array}{l}{[0.41,0.65]} \\
{[0.11,0.16]}\end{array}$ & $\begin{array}{l}{[0.21,0.56]} \\
{[0.05,0.25]}\end{array}$ & $\begin{array}{l}{[0.16,0.22],} \\
{[0.47,0.65]}\end{array}$ \\
\hline & $h_{4}$ & $\begin{array}{l}{[0.51,0.62]} \\
{[0.11,0.13]}\end{array}$ & $\begin{array}{l}{[0.52,0.63],} \\
{[0.03,0.13]}\end{array}$ & $\begin{array}{l}{[0.66,0.71],} \\
{[0.03,0.05]}\end{array}$ & $\begin{array}{l}{[0.11,0.32]} \\
{[0.35,0.46]}\end{array}$ & $\begin{array}{l}{[0.35,0.50]} \\
{[0.13,0.30]}\end{array}$ & $\begin{array}{l}{[0.13,0.42]} \\
{[0.38,0.49]}\end{array}$ & $\begin{array}{l}{[0.55,0.65],} \\
{[0.23,0.31]}\end{array}$ \\
\hline & $h_{5}$ & $\begin{array}{l}{[0.30,0.42]} \\
{[0.04,0.09]}\end{array}$ & $\begin{array}{l}{[0.26,0.46],} \\
{[0.12,0.15]}\end{array}$ & $\begin{array}{l}{[0.42,0.57],} \\
{[0.23,0.31]}\end{array}$ & $\begin{array}{l}{[0.51,0.73]} \\
{[0.02,0.20]}\end{array}$ & $\begin{array}{l}{[0.52,0.61]} \\
{[0.22,0.30]}\end{array}$ & $\begin{array}{l}{[0.35,0.50]} \\
{[0.25,0.32]}\end{array}$ & $\begin{array}{l}{[0.20,0.58],} \\
{[0.10,0.32]}\end{array}$ \\
\hline \multirow{5}{*}{$r^{4}$} & $h_{1}$ & $\begin{array}{l}{[0.42,0.61]} \\
{[0.12,0.15]}\end{array}$ & $\begin{array}{l}{[0.51,0.76],} \\
{[0.03,0.20]}\end{array}$ & $\begin{array}{l}{[0.42,0.60],} \\
{[0.12,0.33]}\end{array}$ & $\begin{array}{l}{[0.15,0.22]} \\
{[0.20,0.38]}\end{array}$ & $\begin{array}{l}{[0.31,0.52]} \\
{[0.11,0.25]}\end{array}$ & $\begin{array}{l}{[0.70,0.72]} \\
{[0.12,0.18]}\end{array}$ & $\begin{array}{l}{[0.42,0.61],} \\
{[0.25,0.33]}\end{array}$ \\
\hline & $h_{2}$ & $\begin{array}{l}{[0.38,0.55]} \\
{[0.11,0.23]}\end{array}$ & $\begin{array}{l}{[0.26,0.51],} \\
{[0.11,0.14]}\end{array}$ & $\begin{array}{l}{[0.52,0.70],} \\
{[0.01,0.23]}\end{array}$ & $\begin{array}{l}{[0.20,0.45]} \\
{[0.40,0.41]}\end{array}$ & $\begin{array}{l}{[0.45,0.50]} \\
{[0.22,0.23]}\end{array}$ & $\begin{array}{l}{[0.24,0.30]} \\
{[0.40,0.61]}\end{array}$ & $\begin{array}{l}{[0.15,0.21],} \\
{[0.43,0.51]}\end{array}$ \\
\hline & $h_{3}$ & $\begin{array}{l}{[0.61,0.72]} \\
{[0.02,0.05]}\end{array}$ & $\begin{array}{l}{[0.72,0.92],} \\
{[0.01,0.06]}\end{array}$ & $\begin{array}{l}{[0.56,0.70],} \\
{[0.21,0.26]}\end{array}$ & $\begin{array}{l}{[0.13,0.30]} \\
{[0.26,0.42]}\end{array}$ & $\begin{array}{l}{[0.43,0.52]} \\
{[0.21,0.27]}\end{array}$ & $\begin{array}{l}{[0.52,0.60]} \\
{[0.08,0.12]}\end{array}$ & $\begin{array}{l}{[0.09,0.12],} \\
{[0.45,0.66]}\end{array}$ \\
\hline & $h_{4}$ & $\begin{array}{l}{[0.12,0.31]} \\
{[0.36,0.40]}\end{array}$ & $\begin{array}{l}{[0.40,0.61],} \\
{[0.12,0.28]}\end{array}$ & $\begin{array}{l}{[0.21,0.54],} \\
{[0.37,0.39]}\end{array}$ & $\begin{array}{l}{[0.50,0.71]} \\
{[0.26,0.38]}\end{array}$ & $\begin{array}{l}{[0.20,0.30]} \\
{[0.24,0.27]}\end{array}$ & $\begin{array}{l}{[0.44,0.49]} \\
{[0.21,0.24]}\end{array}$ & $\begin{array}{l}{[0.42,0.53],} \\
{[0.33,0.35]}\end{array}$ \\
\hline & $h_{5}$ & $\begin{array}{l}{[0.22,0.57]} \\
{[0.02,0.25]}\end{array}$ & $\begin{array}{l}{[0.57,0.66],} \\
{[0.13,0.15]}\end{array}$ & $\begin{array}{l}{[0.50,0.57],} \\
{[0.31,0.40]}\end{array}$ & $\begin{array}{l}{[0.15,0.24]} \\
{[0.55,0.62]}\end{array}$ & $\begin{array}{l}{[0.34,0.51]} \\
{[0.21,0.26]}\end{array}$ & $\begin{array}{l}{[0.26,0.35]} \\
{[0.15,0.20]}\end{array}$ & $\begin{array}{l}{[0.16,0.23],} \\
{[0.34,0.39]}\end{array}$ \\
\hline \multirow{5}{*}{$r^{5}$} & $h_{1}$ & $\begin{array}{l}{[0.42,0.78]} \\
{[0.12,0.20]}\end{array}$ & $\begin{array}{l}{[0.39,0.53],} \\
{[0.25,0.30]}\end{array}$ & $\begin{array}{l}{[0.42,0.55],} \\
{[0.05,0.21]}\end{array}$ & $\begin{array}{l}{[0.13,0.32]} \\
{[0.34,0.38]}\end{array}$ & $\begin{array}{l}{[0.32,0.36]} \\
{[0.30,0.39]}\end{array}$ & $\begin{array}{l}{[0.22,0.35]} \\
{[0.31,0.39]}\end{array}$ & $\begin{array}{l}{[0.45,0.48],} \\
{[0.21,0.25]}\end{array}$ \\
\hline & $h_{2}$ & $\begin{array}{l}{[0.30,0.36]} \\
{[0.02,0.11]}\end{array}$ & $\begin{array}{l}{[0.50,0.57],} \\
{[0.20,0.31]}\end{array}$ & $\begin{array}{l}{[0.35,0.42],} \\
{[0.22,0.30]}\end{array}$ & $\begin{array}{l}{[0.42,0.46]} \\
{[0.31,0.35]}\end{array}$ & $\begin{array}{l}{[0.52,0.69]} \\
{[0.21,0.30]}\end{array}$ & $\begin{array}{l}{[0.52,0.67]} \\
{[0.21,0.30]}\end{array}$ & $\begin{array}{l}{[0.38,0.58],} \\
{[0.10,0.24]}\end{array}$ \\
\hline & $h_{3}$ & $\begin{array}{l}{[0.42,0.55]} \\
{[0.35,0.37]}\end{array}$ & $\begin{array}{l}{[0.36,0.38],} \\
{[0.15,0.20]}\end{array}$ & $\begin{array}{l}{[0.17,0.28],} \\
{[0.32,0.40]}\end{array}$ & $\begin{array}{l}{[0.22,0.32]} \\
{[0.38,0.45]}\end{array}$ & $\begin{array}{l}{[0.41,0.46]} \\
{[0.20,0.25]}\end{array}$ & $\begin{array}{l}{[0.41,0.48]} \\
{[0.20,0.25]}\end{array}$ & $\begin{array}{l}{[0.60,0.78],} \\
{[0.15,0.18]}\end{array}$ \\
\hline & $h_{4}$ & $\begin{array}{l}{[0.12,0.46]} \\
{[0.30,0.32]}\end{array}$ & $\begin{array}{l}{[0.22,0.48],} \\
{[0.31,0.44]}\end{array}$ & $\begin{array}{l}{[0.71,0.85],} \\
{[0.03,0.07]}\end{array}$ & $\begin{array}{l}{[0.26,0.37]} \\
{[0.05,0.10]}\end{array}$ & $\begin{array}{l}{[0.57,0.60]} \\
{[0.06,0.14]}\end{array}$ & $\begin{array}{l}{[0.57,0.60]} \\
{[0.06,0.15]}\end{array}$ & $\begin{array}{l}{[0.51,0.71],} \\
{[0.10,0.21]}\end{array}$ \\
\hline & $h_{5}$ & $\begin{array}{l}{[0.11,0.14]} \\
{[0.37,0.40]}\end{array}$ & $\begin{array}{l}{[0.42,0.63],} \\
{[0.20,0.21]}\end{array}$ & $\begin{array}{l}{[0.55,0.62],} \\
{[0.07,0.14]}\end{array}$ & $\begin{array}{l}{[0.43,0.56]} \\
{[0.09,0.12]}\end{array}$ & $\begin{array}{l}{[0.80,0.91]} \\
{[0.02,0.06]}\end{array}$ & $\begin{array}{l}{[0.80,0.91]} \\
{[0.02,0.06]}\end{array}$ & $\begin{array}{l}{[0.22,0.35],} \\
{[0.40,0.43]}\end{array}$ \\
\hline
\end{tabular}

Table 3. Weighting table of indicators for the selection of military-civilian scientific and technological collaborative innovation partners.

\begin{tabular}{cccccccc}
\hline Indicators Weight & $g_{1}$ & $g_{2}$ & $g_{3}$ & $g_{4}$ & $g_{5}$ & $g_{6}$ & $g_{7}$ \\
\hline$\widetilde{\omega}^{1}$ & 0.126 & 0.129 & 0.133 & 0.149 & 0.158 & 0.148 & 0.157 \\
$\widetilde{\omega}^{2}$ & 0.107 & 0.144 & 0.161 & 0.144 & 0.160 & 0.145 & 0.139 \\
$\widetilde{\omega}^{3}$ & 0.127 & 0.124 & 0.140 & 0.152 & 0.148 & 0.134 & 0.175 \\
$\widetilde{\omega}^{4}$ & 0.132 & 0.115 & 0.113 & 0.166 & 0.112 & 0.135 & 0.226 \\
$\widetilde{\omega}^{5}$ & 0.146 & 0.111 & 0.136 & 0.234 & 0.124 & 0.127 & 0.122 \\
\hline
\end{tabular}

According to the expert evaluation data in Table 2 and the index weight values in Table 3, the comprehensive decision matrix $R=\left(r_{i j}\right)_{5 \times 7}$ is obtained by combining Equation (18). 


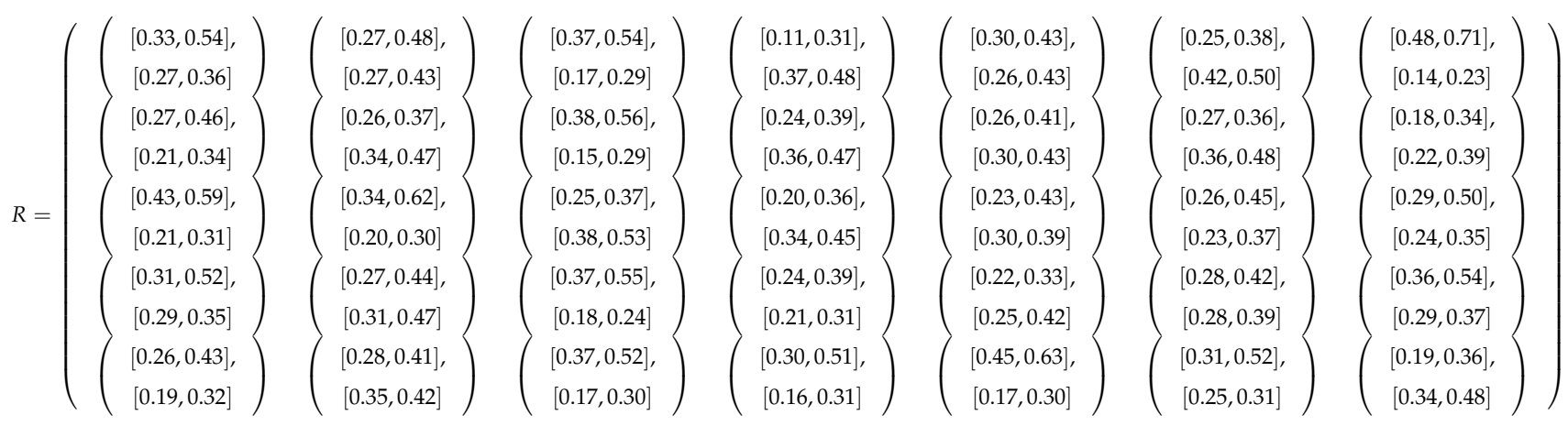

Here we take the risk-neutral attitude of decision-makers as an example for analysis, and take $\theta=0.5$. According to the hesitation distribution method proposed by Equations (19)-(23), the intuitionistic fuzzy matrix $\widetilde{T}=\left(\widetilde{t}_{i j}\right)_{5 \times 7}$ can be obtained.

$$
\widetilde{T}=\left(\begin{array}{ccccccc}
(0.10,0.90) & (0.09,0.91) & (0.12,0.88) & (0.07,0.93) & (0.11,0.89) & (0.08,0.92) & (0.18,0.82) \\
(0.08,0.92) & (0.08,0.92) & (0.15,0.85) & (0.08,0.92) & (0.10,0.90) & (0.08,0.92) & (0.09,0.91) \\
(0.12,0.88) & (0.11,0.89) & (0.08,0.92) & (0.08,0.92) & (0.10,0.90) & (0.10,0.90) & (0.13,0.87) \\
(0.10,0.90) & (0.07,0.93) & (0.11,0.89) & (0.12,0.88) & (0.07,0.93) & (0.09,0.91) & (0.17,0.83) \\
(0.11,0.89) & (0.07,0.93) & (0.12,0.88) & (0.19,0.81) & (0.12,0.88) & (0.10,0.90) & (0.07,0.93)
\end{array}\right)
$$

The positive and negative ideal solutions are determined by combining Equations (24) and (25), based on the data in $\widetilde{T}=\left(\widetilde{t}_{i j}\right)_{5 \times 7}$.

$$
\begin{gathered}
f_{j}^{+}=\left[\left(\begin{array}{c}
0.12, \\
0.88
\end{array}\right),\left(\begin{array}{c}
0.11, \\
0.89
\end{array}\right),\left(\begin{array}{c}
0.15 \\
0.85
\end{array}\right),\left(\begin{array}{c}
0.19 \\
0.81
\end{array}\right),\left(\begin{array}{c}
0.12 \\
0.88
\end{array}\right),\left(\begin{array}{c}
0.10 \\
0.90
\end{array}\right),\left(\begin{array}{c}
0.18 \\
0.82
\end{array}\right)\right] \\
f_{j}^{-}=\left[\left(\begin{array}{c}
0.08, \\
0.92
\end{array}\right),\left(\begin{array}{c}
0.07, \\
0.93
\end{array}\right),\left(\begin{array}{c}
0.08, \\
0.92
\end{array}\right),\left(\begin{array}{c}
0.07, \\
0.93
\end{array}\right),\left(\begin{array}{c}
0.07, \\
0.93
\end{array}\right),\left(\begin{array}{c}
0.08, \\
0.92
\end{array}\right),\left(\begin{array}{c}
0.07 \\
0.93
\end{array}\right)\right]
\end{gathered}
$$

The distance between the candidate partner and the positive and negative ideal solution is calculated according to Equations (26) and (27).

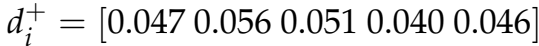

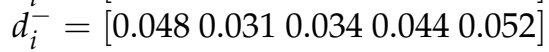

The gray correlation degree between the candidate partners and the positive and negative ideal solutions is calculated according to Equations (28)-(31).

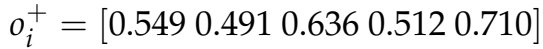

$$
\begin{aligned}
& o_{i}^{-}=\left[\begin{array}{lllll}
0.613 & 0.685 & 0.553 & 0.623 & 0.551
\end{array}\right]
\end{aligned}
$$

The Euclidean distance and gray correlation degree are processed in a dimensionless manner according to Equations (32)-(38), and $\xi=\eta=0.5$. We can obtain the comprehensive closeness of the candidate partners under the condition of neutral risk attitude of the decision maker.

$$
Z_{i}^{+}=\left[\begin{array}{llll}
0.530 & 0.429 & 0.5110 .528 & 0.588
\end{array}\right]
$$

Ranking the five private companies according to the size of their comprehensive closeness, the greater the closeness indicates that the enterprise is more suitable to be selected as the partner of MCSTCI; the smaller the closeness indicates that the enterprise is not suitable to participate in the civil-military integration project. According to the calculation results, it can be seen that the ranking of five private enterprises in this innovation entity selection activity is $h_{5} \succ h_{1} \succ h_{4} \succ h_{3} \succ h_{2}$. Therefore, enterprise 5 should be selected as the partner of this joint R\&D of anti-ship missiles.

The parameters set in the above calculation examples are $\alpha=0.5, \beta=0.25, \theta=0.5$, $\rho=0.5, \xi=0.5$, and $\eta=0.5$. The setting of these parameters is determined by the decision 
maker. $\alpha$ and $\beta$ respectively represent the degree to which the decision maker considers that the accuracy function and interval length affect the improved scoring function; $\theta$ indicates whether the decision maker takes the radical, neutral, or conservative attitude towards the data in the expert evaluation matrix; $\rho$ represents the discriminant coefficient in the gray correlation matrix; $\xi$ and $\eta$ represent the degree of decision maker's preference for distance and correlation, respectively. The parameter settings of the calculation examples in this paper represent the most common situation, while in the actual decision-making process, decision makers can set these parameters independently according to their decision needs. Different decision makers will also focus on different parameter settings. In order to illustrate the influence of the parameter settings on the decision results, the following takes the risk preference coefficients of different decision-makers as examples, takes $\theta=0.8$ and $\theta=0.2$ respectively. Applying the model of this paper and comparing the results with those of the calculation example $\theta=0.5$, Table 4 can be obtained.

Table 4. Decision makers' ranking of solutions under different risk attitudes.

\begin{tabular}{cccc}
\hline Decision Maker's Risk Attitude & $\boldsymbol{\theta}$ & Degree of Comprehensive Closeness & Ranking of Candidate Partners \\
\hline risk-seeking attitude & 0.8 & $(0.4550 .3950 .4440 .4580 .558)$ & $h_{5} \succ h_{4} \succ h_{1} \succ h_{3} \succ h_{2}$ \\
\hline risk-neutral attitude & 0.5 & $(0.5300 .4290 .5110 .5280 .588)$ & $h_{5} \succ h_{1} \succ h_{4} \succ h_{3} \succ h_{2}$ \\
\hline risk-averse attitude & 0.2 & $(0.5160 .4020 .5020 .5080 .538)$ & $h_{5} \succ h_{1} \succ h_{4} \succ h_{3} \succ h_{2}$ \\
\hline
\end{tabular}

As seen in Table 4, the different risk attitudes of decision makers have an impact on the ranking of candidate partners. Specifically, both risk-neutral and risk-averse decision makers come up with the ranking of candidate partners that are $h_{5} \succ h_{1} \succ h_{4} \succ h_{3} \succ h_{2}$, and when the decision maker is risk-seeking, the ranking of $h_{4}$ has improved, replacing $h_{1}$ to become second. In terms of degree of comprehensive closeness, $h_{5}$ is much higher than other candidates, and $h_{2}$ is much lower than other candidates, and $h_{1}, h_{3}$, and $h_{4}$ are relatively close. This difference is caused by the raw data evaluated by experts, indicating that $h_{5}$ has an absolute advantage, and its ranking will not change due to different risk attitudes of decision makers. However, if the raw evaluation values given by the experts to the candidates are relatively close, the ranking results obtained by decision makers with different risk attitudes may be significantly different. Although the best partners of the three types of decision makers in the calculation examples are all $h_{5}$, if the military equipment manufacturing enterprise chooses more than one partner, the final decision result will be different. Therefore, the different risk attitudes of decision makers will have an impact on the results of decision-making. It is reasonable and necessary to consider the risk attitude of decision makers in the decision-making process.

\section{Discussion}

MCSTCI is a new organizational model that responds to the coordinated development of national defense construction and economic construction, and carries out major national scientific and technological research. Partner selection among military-civilian innovation entities has become a critical and very complex task. To this end, in accordance with the principles of index design, combining the top-level design, the main characteristics and technical characteristics of the partners, and interaction between cooperative entities, this paper selects seven categories of indicators including civil-military integration policy, technology policy and operating mechanism, civil-military integration willingness, organizational structure (unit nature), technological innovation level, technology transfer capability, collaborative configuration of elements, benefit distribution model to design the evaluation index system of MCSTCI. This index system can better reflect the current innovation capability and continuous innovation capability of the candidate partners in the process of MCSTCI. Secondly, for the problem of the multi-attribute group decision-making, an improved scoring function and entropy weighting method are proposed to determine the objective weights of indicators, and the risk attitude of decision makers is considered, 
combined with gray correlation and TOPSIS method to rank the selected partners. This method provides a scientific paradigm of partner selection for innovation entities, and promotes the integration of scientific and technological resources. Finally, as a numerical example, partner selection for a military equipment manufacturing enterprise in Beijing is conducted to verify the effectiveness and practical application value of the military-civilian technological collaborative innovation partner selection model. Therefore, in the face of major national strategic needs, this model can be applied in practice to select partners more scientifically and rationally, so as to solve major frontier scientific problems.

\section{Conclusions}

Partner selection is an important basic link to carry out the MCSTCI activities. On the basis of summarizing and sorting out the influencing indicators, this paper constructs an MCSTCI partner selection model based on interval intuitionistic fuzzy set theory from the perspective of multi-attribute decision making. Compared with previous multi-attribute decision models, the superiority of the proposed model is reflected in the following aspects: (1) The proposed improved scoring function integrates the influence of accuracy function and interval length, which can reflect the characteristics of an interval intuitionistic fuzzy number more comprehensively and accurately compared with the traditional scoring function. (2) Combining the improved scoring function and entropy weight method to determine the objective weight of each indicator, the model can make full use of the information of each interval intuitionistic fuzzy numbers and eliminate the subjective influence of weighting. (3) This model considers the influence of decision maker's risk attitude on the decision results, and transforms the interval intuitionistic fuzzy matrix into intuitionistic fuzzy matrix by assigning hesitation degree, which can simplify the calculation process. (4) Combining the gray correlation method and TOPSIS method to rank each candidate partner, the method has better distinguishing ability and conforms to the objective reality, compared with the scoring function ranking method and the traditional TOPSIS method. Numerical examples show that the model proposed in this paper is more comprehensive and flexible in solving fuzzy multi-attribute decision problems, and is suitable for the selection of MCSTCI partners.

However, there are still some shortcomings that can be improved in this paper. Regarding the selection of MCSTCI indicators, this paper summarizes four first-level indicators and seven second-level indicators, considering the limitation of space and calculation examples. In fact, the division of indicators for the selection of military-civilian MCSTCI partners can be more detailed and accurate, and further research will be done on the construction of indicator systems. In addition, the model proposed in this paper is a single static evaluation decision model. The practice of selecting MCSTCI partners shows that the decision-making process is often a multi-stage dynamic evaluation, and even rolling evaluation and halfway termination of cooperation occur. Therefore, future work will focus on exploring the dynamic selection model of MCSTCI partners.

Author Contributions: B.L., J.Z. worked collectively; B.L. conceived and designed the study with the support of J.Z.; J.Z. gave constructive suggestions for the idea and the writing. All authors have read and agreed to the published version of the manuscript.

Funding: This research was funded by National Natural Science Foundation of China: 71841051; Major Strategic Research and Consulting Project of Chinese Academy of Engineering: 2020-ZD-1; Beijing Institute of Technology Military-civilian Scientific Technological Collaborative Innovation Research Production-University-Research Joint Training Base Project: LHPYJD1801.

Institutional Review Board Statement: Not applicable.

Informed Consent Statement: Not applicable.

Data Availability Statement: Not applicable.

Acknowledgments: The authors would like to thank the anonymous reviewers for their valuable comments which increased this paper's quality. 
Conflicts of Interest: The authors declare no conflict of interest.

\section{References}

1. Shang, Q.M. "The pillars of a great power" shows "China power". Outlook 2017, 18, 4.

2. Zhao, H.Z.; Shu, H.F. The Guardian of Science in National Affairs-On the "Big Science" of the United States. Sci. Sci. Manag. S T 1994, 15, 40-44.

3. Jinping, X. Secure a Decisive Victory in Building a Moderately Prosperous Society in All Respects and Strive for the Great Success of Socialism with Chinese Characteristics for a New Era. Engl. Ed. Qiushi J. 2018, 10, 34.

4. Yi, B.Y.; Huang, S.L.; Lei, E.Q. The way how DARPA takes the leadership in national defense science and technology innovation. Sci. Technol. Rev. 2018, 36, 33-36.

5. Lv, H.J.; Gan, Z.X. Civil-Military Integration and Dual-Use Policy Implications in the Evolution Process of National Innovation System in America and Japan. China Soft Sci. 2005, 6, 43-46.

6. Osborn, A. Russia Returns to Commercial Airline Market: Consolidation Key to Wider Strategy. Wash. Post 2007, 6, 26.

7. Li, L.; Xie, J.; Wang, R.; Su, J.; Sindakis, S. The Partner Selection Modes for Knowledge-Based Innovation Networks: A Multiagent Simulation. IEEE Access 2019, 7, 140969-140979. [CrossRef]

8. Sun, F.; Liu, S.; Zhu, X.; Men, B. Research and progress of Beidou satellite navigation system. Sci. China Inf. Sci. 2012, 55, 2899-2907. [CrossRef]

9. Mai, Q.; Chen, X.; An, S. Integrity, complexity and system integration of major aerospace engineering: The practice of Beidou satellite engineering. Manag. World 2019, 35, 196-204.

10. Zhou, Y.; Zhou, D.M.; Ding, Y.W.; Ruoyu, L. Research on the path evolution and driving factors of military-civilian integration technology transfer-“"Zhong Wu-Tech" 2004-2017 case study. Manag. Rev. 2020, 32, 323-336.

11. Fang, W.; Xiao, L.M.; Yang, B. An empirical study of influencing factors on civil-involved military knowledge transfer: A perspective of civil-military integration collaborative innovation. Stud. Sci. Sci. 2019, 39, 664-678.

12. Kulve, H.T.; Smit, W.A. Civilian-military cooperation strategies in developing new technologies. Res. Policy 2003, 32, 955-970. [CrossRef]

13. Zhao, L.M.; Sun, J.H.; Zhang, H.B. Technology sharing behavior in civil-military integration collaborative innovation system based on differential game. J. Ind. Eng. Eng. Manag. 2017, 31, 183-191.

14. Fang, W.; Wang, C. The Cooperative Stability Evolutionary Game Analysis of the Military-Civilian Collaborative Innovation for China's Satellite Industry. Math. Probl. Eng. 2019, 3. [CrossRef]

15. Zhao, Z.B.; Han, C.Q.; Wang, L.Q. Collaborative innovation network of defence-related science and technology industry alliance: Structure and evolution. J. Public Manag. 2019, 16, 156-167.

16. Wang, P.P.; Chen, B. Study on technical efficiency and its antecedents of civilian-military integrated firms. Bus. Rev. 2019, 31, 70-82.

17. Lavallee, T.M. Civil-Military Integration: The Politics of Outsourcing National Security. Bull. Sci. Technol. Soc. 2010, 30, 10-13. [CrossRef]

18. Lv, B.; Qi, X.G. Research on partner combination selection of the supply chain collaborative product innovation based on product innovative resources. Comput. Ind. Eng. 2019, 128, 245-253. [CrossRef]

19. Nikghadam, S.; Sadigh, B.L.; Ozbayoglu, A.M.; Unver, H.O.; Kilic, S.E. A survey of partner selection methodologies for virtual enterprises and development of a goal programming-based approach. Int. J. Adv. Manuf. Technol. 2016, 85, 1713-1734. [CrossRef]

20. Han, Y.; Chen, G.H. Research of knowledge sharing partner selection in cluster enterprises based on invisible contract. Chin. J. Manag. Sci. 2018, 26, 179-185.

21. Zhu, Q.; Yang, Y.; He, Q.S.; Qu, S.Y. Research on the selection of innovation allies in internet + projects based on ELECTRE-I method. China Soft Sci. 2016, 4, 143-149.

22. Xiao, J.; Niu, Y.; Chen, P.; Leung, S.C.; Xing, F. An improved gravitational search algorithm for green partner selection in virtual enterprises. Neurocomputing 2016, 217, 103-109. [CrossRef]

23. Atanassov, K.T. Intuitionistic fuzzy sets. Fuzzy Sets Syst. 1986, 20, 87-96. [CrossRef]

24. Atanassov, K.T.; Gargov, G. Interval-valued intuitionistic fuzzy sets. Fuzzy Sets Syst. 1989, 31, 343-349. [CrossRef]

25. Fu, X.L.; Ouyang, T.X.; Yang, Z.L.; Liu, S. A product ranking method combining the features opinion pairs mining and intervalvalued Pythagorean fuzzy sets. Appl. Soft Comput. 2020, 97, 106803. [CrossRef]

26. Chen, X.H.; Zhao, C.C.; Yang, L. A group decision-making model based on interval-valued intuitionistic fuzzy numbers and its application on social network. Syst. Eng. Theory Pract. 2017, 37, 1842-1852.

27. Hu, K.; Tan, Q.; Zang, T.; Wang, S. Assessing technology portfolios of clean energy-driven desalination-irrigation systems with interval-valued intuitionistic fuzzy sets. Renew. Sustain. Energy Rev. 2020, 132, 109950. [CrossRef]

28. Narayanamoorthy, S.; Geetha, S.; Rakkiyappan, R.; Joo, Y.H. Interval-valued intuitionistic hesitant fuzzy entropy based VIKOR method for industrial robots selection. Expert Syst. Appl. 2019, 121, 28-37. [CrossRef]

29. Gong, R.Z.; Ma, L.Y. A new score function and accuracy function of interval-valued intuitionistic fuzzy number and its application. Syst. Eng. Theory Pract. 2019, 39, 463-475.

30. Gao, J.W.; Liu, H.H.; Gu, Y.D. Interval-valued intuitionistic fuzzy multi-criteria decision-making method based on prospect thoery. Syst. Eng. Theory Pract. 2014, 34, 3175-3181. 
31. Chen, S.M.; Huang, Z.C. Multiattribute decision making based on interval-valued intuitionistic fuzzy values and linear programming methodology. Inf. Sci. Inf. Sci. 2017, 381, 341-351. [CrossRef]

32. Zhou, H.; Ma, X.; Zhou, L.; Chen, H.; Ding, W. A Novel Approach to Group Decision-Making with Interval-Valued Intuitionistic Fuzzy Preference Relations via Shapley Value. Int. J. Fuzzy Syst. 2018, 20, 1172-1187. [CrossRef]

33. Xu, Z.S. Methods for aggregating interval-valued intuitionistic fuzzy information and their application to decision making Control Decis. 2007, 22, 215-219.

34. Zhao, F.X. Distances between Interval-Valued Intuitionistic Fuzzy Sets. Micro Electron. Comput. 2010, $27,188-192$.

35. You, G.R.; Zhao, L.B. Integrated Development of Civil-Military Science and Technology: Theory and Practice; Nation Defense Industry Press: Beijing, China, 2017.

36. Shen, H.Y.; Zheng, X.P. The establishment and empirical study on the evaluation system of scientific and technological innovation ability from the perspective of military-civilian integration. Reform Econ. Syst. 2019, 214, 140-146.

37. Tian, Q.F.; Zhang, T.; Zhang, S.; Miao, D.D. Research on elements fusion mechanism of dual-use science and technology collaborative innovation. Sci. Technol. Prog. Policy 2020, 37, 136-145.

38. Jiang, L.; Yang, P.P.; Zhang, Q.P. Research on the influence mechanism of civil-military fusion innovation for UAV. Sci. Sci. Manag. S T 2018, 39, 96-111.

39. Chen, X.H.; Zhou, K. Analysis of regional innovation efficiency and the influencing factors in civil-military integration in China-An analysis based on random frontier panel data model. Shanghai J. Econ. 2019, 9, 69-79.

40. Yin, J.; Tan, Q.M. A research on the evaluation of the degree of civil-military integration and its optimization measures. Sci. Res. Manag. 2020, 41, 90-97.

41. Hansen, L.P.; Sargent, T. Robustness; Princeton University Press: New York, NY, USA, 2008.

42. Nicholson, W.; Snyder, C. Microeconomic Theory Basic Principles and Extensions, 12th ed.; Cengage Learning: Boston, MA, USA, 2017; pp. 212-221. 